\title{
Conceptualizing and measuring distance in international business research: Recurring questions and best practice guidelines
}

\author{
Sjoerd Beugelsdijk ${ }^{1}$, \\ Björn Ambos ${ }^{2}$ and \\ Phillip C Nell ${ }^{3}$
}

\footnotetext{
${ }^{1}$ Faculty of Economics and Business, University of Groningen, Groningen, The Netherlands;

${ }^{2}$ University of St. Gallen, St. Gallen, Switzerland;

${ }^{3}$ WU Vienna, Vienna, Austria
}

Correspondence:

$S$ Beugelsdijk, Faculty of Economics and

Business, University of Groningen,

Groningen, The Netherlands.

Tel: +31 5036 39095;

Fax: +31(0) 50363 2920;

e-mail: s.beugelsdijk@rug.nl

\begin{abstract}
Distance is a central concept in international business research, yet there is debate about the construct as well as its operationalization. In this editorial, we address three of the most important recurring questions posed by authors, editors, and reviewers by examining the theory, methods, and data of distance research. We discuss (1) how to theorize on distance, and (2) what method and (3) what data to use when constructing a distance index. We develop practical recommendations grounded in theory, illustrating and supporting them by calculating cross-country distance indices for all available country pairs and two of the most used distance indices: cultural and institutional. We show that, whereas a specific method to calculate distance may matter to some extent, the choice for a specific cultural or institutional framework to measure cultural or institutional distance has a major impact on country-pair distances. Overall, this editorial highlights the importance of matching data and method to the theoretical argument.
\end{abstract}

Journal of International Business Studies (2018) 49, I I I 3-I I 37. https://doi.org/10.1057/s41267-018-0182-4

Keywords: distance; cultural distance; institutional distance; Euclidean; Mahalanobis; Kogut-Singh index

The online version of this article is available Open Access

\section{INTRODUCTION}

Distance may well have become an international business research workhorse (Salomon, 2016; Verbeke, Puck, \& van Tulder, in press), but the distance construct as well as its operationalization are continuously being debated in practice (Kirkman, Lowe \& Gibson, 2006; Shenkar, 2001; Zaheer, Schomaker \& Nachum, 2012). That debate can be quite impassioned. Some find the use of a composite cultural distance index appropriate (e.g., Cuypers, Ertug, Heugens, Kogut \& Zou, 2018), while others reject this outright as a vestige of the "dark middle ages" of crosscultural research (Tung \& Verbeke, 2010: 1270). Similar debates exist around other aspects of distance research. Some of these debates seem unresolved and complex, and it is our experience that authors, reviewers, and editors respond to these issues differently.

In this editorial, we address recurring disagreement on theory, methods, data, and the relationship between different distance 
dimensions, complementing and updating existing editorials (Beugelsdijk \& Mudambi, 2013; Zaheer et al., 2012), commentaries (Brouthers, Marshall \& Keig, 2016; Van Hoorn \& Maseland, 2016), debates (Cuypers et al., 2018; Maseland, Steel, \& Dow, 2018), and surveys of distance research (Berry, Guillen, \& Zhou 2010; Hutzschenreuter, Kleindienst, \& Lange, 2014; Shenkar, 2001; Tung \& Verbeke, 2010). We then make a series of recommendations which we believe will help achieve convergence in research practice.

Our recommendations center on: (1) how to theorize on distance, and (2) what method and (3) what data to use to calculate a distance index. Where relevant and possible, we support our argument by leveraging all available country-pair data on the most used distance dimensions. While we discuss distance in a broad sense, we illustrate our points predominantly by drawing on cultural and institutional distance. Nonetheless, we think that our reasoning and recommendations are relevant for other types of distance. Our goal is to set out a disciplined approach to crafting and reviewing distance studies in a positive and constructive way. We summarize and elaborate on current practices, explain the nature of the debate regarding distance, and, where we can, provide best practice guidelines. The data that we use are available on the website of the Journal of International Business Studies for replication and extension purposes.

\section{DISTANCE RESEARCH IN INTERNATIONAL BUSINESS}

In principle, distance can be measured between any two entities, be it individuals, teams, organizations, nations, ethnic groups, language groups, even organizational fields. In most international business and management research, the distance measured is between countries. Zaheer et al. (2012: 19) define international management as "management of distance". The attractiveness of distance is rooted in its literal meaning related to geographic or physical distance, and its metaphorical one (Shenkar, 2012) referring to "the collective differences between countries" (Zaheer et al., 2012: 20). The importance of country as a unit of analysis also applies to psychic distance, which can be defined as the perceived distance that individuals or groups hold regarding a particular country (Dow \& Karunaratna, 2006; Håkanson, Ambos, Schuster, \& Leicht-Deobald, 2016).
The origins of the inter-country distance concept can be traced back to early work in international economics. Geographic distance plays an important role in the gravity models commonly used in classic and modern trade theory to explain trade flows between countries (Anderson \& van Wincoop, 2003; Bergstrand, 1985; Feenstra, Markusen \& Rose, 2001). Beckerman (1956) suggested that psychic distance can partly explain intra-European trade, thereby extending the meaning of distance beyond its geographical dimension. Interestingly, the empirical evidence for Beckerman's 1956 claim that distance perceptions explain trade flows is relatively recent (Dow \& Karunaratna, 2006; Guiso, Sapienza \& Zingales, 2009; Håkanson, 2014; Yu, Beugelsdijk \& de Haan, 2015).

Some two decades would pass before Beckerman's concept of psychic distance would be used in international business research. A series of studies published by the Uppsala school (e.g., Johanson \& Vahlne, 1977; Johanson \& Wiedersheim-Paul, 1975) argued that psychic distance significantly influences the location choice and internationalization paths of firms. In one of those studies, Johanson \& Wiedersheim-Paul (1975: 308) define psychic distance as the "sum of factors preventing or disturbing the flow of information between firm and market" (see also Vahlne \& Wiedersheim-Paul, 1973), ${ }^{1}$ a definition that has become a classic in distance research (Dow \& Karunaratna, 2006), and is echoed by Zaheer et al.'s (2012: 20) definition of psychic distance as the "collective differences between countries".

To operationalize their construct, Vahlne and Wiedersheim-Paul (1973) created a compound measure including characteristics of the target market such as GDP per capita, educational level, differences between the home country (in their case, Sweden) and the host country, including language and culture, as well as trade relations measured by the relative level of imports as a further proxy for information flows. ${ }^{2}$ Johanson, Vahlne, and Wiedersheim-Paul's contributions, although seminal, introduced ambiguity in transferring what was originally a perceptual measure that complemented the cost of geographical distance into a measure of objective differences between trading partners (Håkanson \& Ambos, 2010). Although the psychic distance construct as such is generally accepted in international business research and practice, Håkanson \& Kappen (2017) assert that the theoretical predictions of the 
associated Uppsala school of internationalization lack robust empirical support.

A decade later, Kogut \& Singh (1988) introduced a composite cultural distance index based on the country scores for the four national cultural dimensions developed by Hofstede (1980) and Cuypers et al., (2018). They considered their cultural distance index to be in many ways similar to the psychic distance index of the Uppsala school (Kogut \& Singh, 1988: footnote 10). In their original article, the authors were also very explicit about the internal validity of their measure, acknowledging that:

\footnotetext{
The indices of Hofstede can be criticized for a number of reasons, especially regarding the internal validity of the dimensions and the method of constructing the scales. Whereas the criticism has a sound basis, Hofstede's study has some appealing attributes, namely, the size of the sample, the codification of cultural traits along a numerical index, and its emphasis on attitudes in the workplace (Kogut \& Singh, 1988: 422).
}

In the years that followed, the Kogut \& Singh (1988) index was widely adopted, in part because of the ease of calculating it and in part because of increasing use of secondary datasets in international business research (Cuypers et al., 2018). The cultural distance index, which originated as a psychological complement to geographical distance, has become the de facto standard instrument to measure distance in international business studies. Over time, the index has turned into a quasiobjectified, single measure of differences between internationally distant actors (Ambos \& Håkanson, 2014).

The Kogut \& Singh (1988) index has been the subject of serious conceptual and methodological criticism (Kirkman et al., 2006, 2017; Shenkar, 2001, 2012; Maseland et al., 2018). Shenkar (2001) identified a set of weaknesses plaguing it, yet a decade later he would note that a large majority of studies simply cited his criticism of the index in order to "acknowledge" the problem, then went on to use it without any further discussion (Shenkar, 2012).

There have nevertheless been efforts to address problems with the index; for instance, attempts to introduce additional dimensions. Kostova (1996) developed institutional country profiles to ground the concept of institutional distance (e.g., Eden \& Miller, 2004; Xie \& Li, 2017; Xu \& Shenkar, 2002). Ghemawat (2001) introduced the CAGE framework, referring not only to cultural but also to economic, geographic, and administrative distance (Nell \& Ambos, 2013; Mingo, Morales \& Dau, 2018). Others have proposed new metrics to calculate the index (Berry et al., 2010), created new databases with additional dimensions (Dow \& Karunaratna, 2006), and developed perceptionbased psychic distance measures (Håkanson \& Ambos, 2010). Collectively, these advances have been valuable, but there are still many unanswered questions raised by authors, reviewers and editors.

We have organized our discussion of distance research around three questions, for which we provide theoretically-grounded practical recommendations: (1) How should a theoretical framework on distance (e.g., distance in general vs. distance on a specific dimension) be constructed? (2) What method should be used to calculate a distance index, specifically, does (co-) variance correction (e.g., using Mahalanobis distance) affect the results, and if so, how? And (3) what data should be used to construct a distance index, and specifically, does it matter if one chooses a particular dataset of cultural (Hofstede, Schwartz or Globe) and institutional dimensions (e.g., Quality of Governance, Economic Freedom Index, or International Country Risk Guide)?

\section{HOW TO THINK THEORETICALLY ABOUT DISTANCE}

There is no such thing as a general distance theory in the sense of a single, internally consistent set of assumptions, mechanisms, and boundary conditions, but the lack of a single distance theory is no reason to stop exploring the meaning of distance in international business. Similarly, there is no grand theory of national culture, but this has not stopped scholars from investigating the relevance of national culture for international business. ${ }^{3}$ Distance is a construct and as such is meaningful only in the context of a specific theory, be it, for example, agency theory, transaction costs theory, or learning theory. This may appear obvious, but it is important to make it explicit as it has several important implications for theory development.

\section{Distinguishing Between Geographical and Contextual Distance}

As alluded to earlier, we see the concept of distance as the joining of two essential elements of doing business across borders. The first one is the geographic distance between two or more locations. Narrowly defined, geographic distance is the 
distance between two points on the surface of the earth, as given by latitudinal and longitudinal coordinates. In keeping with this definition, geographic distance has three properties: it is (1) symmetrical (i.e. the geographic distance between countries $\mathrm{A}$ and $\mathrm{B}$ is the same as that between countries B and A), (2) continuous, and (3) stable over time.

Second, distance refers to the change in context that occurs when firms cross national borders. In this case, distance serves as a metaphor for the kinds and varying degrees of differences in context (Shenkar, 2012). In contrast to geographic distance, contextual distance can be (1) asymmetric, (2) noncontinuous, and (3) it can change over time. Shenkar (2001) makes the point that the distance from one country to another may be asymmetric (e.g., between a country with a low level of economic development and one with a high level) and that this has implications for internationalizing firms. Similarly, psychic distance research has shown that the perceived distance between country $A$ and country $B$ may be different from that between B and A (Shenkar, 2001; Håkanson \& Ambos, 2010; Håkanson et al. 2016). Contextual distance may also be non-continuous, as it is subject to border effects (Beugelsdijk \& Mudambi, 2013). National borders are powerful discrete delineators of context (Peterson, Søndergaard \& Kara, 2018). ${ }^{4}$ Finally, contextual distance can change over time as countries go through economic, institutional, and cultural change. We will return to this point later, but note here that many distance dimensions have been relatively stable over time.

\section{Spelling Out the Mechanisms}

In addition to distinguishing between geographic and contextual distance, the relationship between theoretical argument and the distance construct must be made explicit (see also Zaheer et al., 2012; Maseland et al., 2018). Distance may have a different meaning in learning theories (Stahl \& Tung, 2015) as compared to agency and transaction cost theories (Kostova, Nell \& Hoenen, 2017; Nell, Kappen, \& Laamanen, 2017; Shenkar, Luo, \& Yeheskel, 2008). While learning theories would emphasize that doing business in a different context can stimulate creativity, agency theory and transaction costs theory would highlight the increased uncertainty, and the potential for misunderstandings. Similarly, a large economic distance may give rise to additional costs, as products and business models must be adapted, but it may also generate arbitrage opportunities (Ghemawat, 2001). Finally, if the argument is that managers prefer to enter countries that are relatively similar to the home country, then perhaps psychic distance (that captures overall perceived dissimilarity) might be the more appropriate construct. Hence, the functional role of distance depends on the type of distance (the specific distance construct) and the theoretical context in which it is used.

Unfortunately, explicit theorizing on the channels through which geographic and/or contextual distance affects outcomes is often underspecified, even missing altogether. For instance, while the standard assumption - whether implicit or explicit - in many studies is that distance results in costs, why that may be true is seldom discussed (Beugelsdijk et al., 2018; Maseland et al., 2018; Zaheer et al., 2012).

\section{Distance as an Aggregate Construct}

Given the multidimensional nature of contextual differences, the question is whether distance should be measured on a specific dimension or as a composite construct. This discussion applies specifically to cultural distance as an index based on the distance between the home and host country on multiple cultural dimensions. In the original Kogut \& Singh (1988) index, four of Hofstede's cultural dimensions were included (individualism-collectivism, power distance, uncertainty avoidance, and masculinity-femininity).

Some have argued against the use of composite distance indices, such as the Kogut and Singh index (Dow \& Karunaratna, 2006; Kirkman et al., 2006), as the dimensions included are conceptually different, and aggregating them makes the composite index imprecise and noisy. Using instead the home-host distance on individual dimensions (for example, the distance on Hofstede's individualism dimension) allows for more precise theorizing. Others counter that the use of composite indices such as the cultural distance index is valuable, composite indices being more tractable and connecting well to prior research (Cuypers et al., 2018). It may be a moot point as the Kogut and Singh cultural distance index has become the de facto research standard, and, as observed by Shenkar (2012), many distance studies simply continue to use it because it has been used before.

In our view, whether one should use a composite index or one based on an individual dimension, hinges on the nature of the theoretical argument. Such an approach is unfortunately often lacking in 
current research practice (for an exception on aspects of cultural distance, see Dikova, Sahib \& van Witteloostuijn, 2010; for an exception on aspects of institutional distance, see Abdi \& Aulakh, 2012). Frequently, a model using individual dimensions of distance is used as a robustness test for a model with composite distance indices (or vice versa) without any discussion of the theoretical implications. We contend that a composite index is required when the nature of the theoretical argument has to do with distance in general. When the theoretical argument involves a specific dimension, for example a difference in degree of individualism, then the authors should address why it matters. For instance, it does not make sense to replace a composite index of distance by one based on individual cultural dimensions if one aims to study the effect of overall cultural distance on the frequency of knowledge exchange among MNE subsidiaries.

An illustration of the difference between theorizing on distance in general or on a specific dimension can be found in Kogut \& Singh (1988). In their study on culture and entry mode choice, they examined the effect on entry mode choice of both overall cultural distance and of uncertainty avoidance (one of the cultural dimensions included in their distance index). ${ }^{5}$ Their first hypothesis builds on the logic that increased cultural distance between two country pairs will foster uncertainties and thus affect entry mode choice. This is a classic argument about overall distance. In their second hypothesis, they suggest that firms from countries that score high on uncertainty avoidance will choose a different entry mode than firms based in countries that score low on that dimension. This example underscores that: (1) arguments on the impact of distance in general will differ from those on a specific dimension of it, and (2) theorizing on individual dimensions will typically require specifying the direction of the effect, in this case from high to low uncertainty avoidance (see Hennart \& Larimo, 1988, for an example of how power distance in the home country affects entry modes in the host country).

\section{Consistency of Distance Effect Assumptions}

More precise theorizing on the mechanisms through which distance affects outcomes is required, as many of the outcomes studied in distance research are the result of multi-stage decision-making processes. In many distance-performance studies, for example, it is argued that distance leads to lower levels of MNE subsidiary or
MNE parent performance because it results in a liability of foreignness, and hence in higher costs of doing business abroad (Beugelsdijk, Nell, \& Ambos, 2017). However, should we not expect distance to have influenced location and entry mode decisions in the first place (Brouthers, 2002)? It is inconsistent from a conceptual perspective to argue that distance affects performance but has no impact on location decisions.

Another example of multi-stage decision-making applies to studies of the impact of distance on the choice of foreign market entry modes. Following transaction costs logic, it is often argued that contextual distance between home and host country will discourage entry with high commitment modes (such as a wholly owned subsidiary) because distance makes access to information and its interpretation more difficult (Morschett, SchrammKlein, \& Swoboda, 2010). However, multinational firms often develop a portfolio of activities in different countries, and the distance between the home country (where the headquarters is located) and the host country of a new foreign entry may not be the most relevant distance with which the multinational firm has to cope (Hendriks, Slangen $\&$ Heugens, 2017). In this case, what matters may be the "added distance", i.e., the distance between the country of the new foreign entry and the closest country in which the firm is already active (Hutzschenreuter, Voll, \& Verbeke, 2011).

These distance-performance and distance-entry mode examples highlight the need to develop a theoretical logic that explains how distance-induced costs and benefits affect the different stages of the firm's internationalization process.

\section{Recommendation}

If we want to make progress, recognizing the need for an explicit discussion of the mechanisms through which a particular type of distance (be it geographic or contextual) affects the phenomenon of interest would appear paramount. This requires taking into account the multi-stage nature of the decision-making process associated with firm internationalization, as well as a careful evaluation of whether the distance we want to study is symmetric (in the case of geographic distance) or asymmetric (in the case of contextual distance). We urge authors to make sure their chosen distance construct is aligned with their theorizing, and not just added to a regression model for convenience purposes. Without such an argumentation, adding a distance variable becomes a pointless exercise. 
Hence, "the use of the aggregate index must be theoretically justified and where appropriate, substituted by cultural distance measures calculated separately for one or more of the five dimensions as necessitated by theoretical and domain considerations" (Shenkar, 2001: 529). The italics are ours, as we want to underscore that one should not use individual dimensions of distance being conceptual equivalents of a composite measure.

\section{HOW TO CONSTRUCT A DISTANCE INDEX}

Kogut and Singh's (1988) cultural distance index (KSIndex) has become a 'must have' variable in international business and management research (Shenkar et al. 2008: 908). It calculates national cultural differences by the composite difference on a set of cultural dimensions (see Kogut \& Singh, 1988: 422):

$$
\operatorname{KSIndex}_{j}=\sum_{i=1}^{n}\left\{\left(I_{i j}-I_{i H O M E}\right)^{2} / V_{i}\right\} / N
$$

where $I_{i j}$ refers to the host country j's mean score on Hofstede's ith dimension, $I i_{H O M E}$ to the home country's mean score on this same dimension, $V_{i}$ to the variance of the $i$ th dimension and $N$ to the number of dimensions. The distance index can be calculated for any multidimensional construct. As we discuss in detail below, the cultural dimensions need not be taken from Hofstede but can also be derived from the Schwartz $(1994,1999,2006)$ or Globe (House et al., 2004) cultural frameworks. The Kogut and Singh formula has been used to operationalize other types of distance besides cultural distance (e.g., regulatory distance in $\mathrm{Wu} \&$ Salomon, 2016; institutional distance in Campbell, Eden \& Miller, 2012).

The Kogut and Singh index belongs to the family of Euclidean distance metrics. Kogut and Singh applied the Euclidean distance metric to measure national cultural differences, but it can be applied to other units of analysis (teams, firms, or subunits). The Kogut and Singh index represents an adaptation of the standard Euclidean method of calculating a composite distance index on a set of individual dimensions. The Euclidean distance between a home country and country $j$ on an $i$ dimensional construct $\mathrm{I}$ is calculated as follows ${ }^{6}$ :

$$
\text { EuclidenDist }_{j}=\sqrt{\sum_{i=1}^{n}\left(I_{i j}-I_{i H O M E}\right)^{2}}
$$

\section{Taking Care of Variance Differences}

The key difference between Eq. 1 and Eq. 2 is the correction for differing variances across the dimensions, because one "problem with Euclidean distance is that it does not take into account the variance of the [individual] variables" (Berry et al., 2010: 1469). That is, the Kogut and Singh index is a Euclidean distance with variance correction. In addition, Kogut and Singh divided the overall distance by the number of dimensions, while the Euclidean distance formula takes the square root of the overall difference.

The Kogut and Singh index and the Euclidean distance index are often presented as alternatives, and therefore used in robustness tests (e.g., Barkema \& Vermeulen, 1997; Drogendijk \& Slangen, 2006). ${ }^{7}$ Below, we illustrate the relationship between these alternative indices for two of the most used distance constructs: (1) cultural distance, and (2) institutional distance.

There are three cross-cultural frameworks used in the management literature. A summary of the key characteristics of each, including their dimensions, can be found in "Appendix A". The first is Hofstede's $(1980,2001)$ well-known cultural framework. The first version consisted of four cultural dimensions, to which an additional two were later added (Hofstede et al., 2010). Whereas the first four dimensions were derived from surveys of IBM employees carried out between 1968 and 1972, the latter two are based on a set of six questions from the World Values Survey-European Value Studies (WVS-EVS). ${ }^{8}$ Berry et al. (2010) and Beugelsdijk, Maseland, \& van Hoorn (2015) have used the WVS-EVS data to develop Hofstede-inspired dimensions. ${ }^{9}$ Schwartz $(1994,1999,2006)$ developed the Schwartz Value Survey, which consists of seven national cultural value orientations. House et al. (2004) developed nine national cultural dimensions for values and for practices, a framework commonly referred to as Globe.

All these culture frameworks can be used to compute cross-country cultural distances. We discuss below whether using the Kogut-Singh formula or the Euclidean distance formula yield radically different results. We calculate the two indices for all country pairs for which data are available. Table 1 shows that the correlations between the Kogut and Singh index (Eq. 1) and the Euclidean distance index (Eq. 2) are very high, ranging from .89 (Globe) to .97 (Hofstede's six dimensions). ${ }^{10}$ 
As mentioned earlier, additional distance constructs have been developed to complement cultural distance, often measured by applying the Kogut and Singh approach. One of these is institutional distance (Eden \& Miller, 2004; Malhotra \& Gaur, 2014; Xie \& Li, 2017; Xu \& Shenkar, 2002), which has been measured using a variety of databases, including the Quality of Governance database (QoG; also referred to as World Governance Indicators) developed by the World Bank (e.g., Kaufmann, Kraay, \& Mastruzzi, 2008; Abdi \& Aulakh, 2012; Ang, Benischke, \& Doh, 2015; Campbell et al., 2012; Hutzschenreuter et al., 2014; Li, Liu, Wright, \& Filatotchev, 2014; Salomon $\& W u, 2012)$, the Economic Freedom Index (EFI) provided by the Heritage Foundation (e.g., Demirbag, Apaydin, \& Tatoglu, 2011; Gubbi, Aulakh, Ray, Sarkar, \& Chittoor, 2010; He, Brouthers, \& Filatotchev, 2013), and the International Country Risk Guide (ICRG) developed by the Political Risk Services group (e.g., Makino \& Tsang, 2011; Valentino, Schmitt, Koch, \& Nell, 2018).

The QoG data consist of six dimensions: rule of law, control of corruption, government effectiveness, voice and accountability, political stability, and regulatory quality. The World Bank calculates standardized country scores for these six dimensions; hence re-scaling the dimensions by correcting for variance differences is not required; however, re-scaling may matter for the EFI-based distance index. The EFI consists of ten indicators of property rights protection, corruption levels, fiscal freedom, government spending, and a set of six indicators measuring freedom of doing business, trade, finance, and investment. EFI scores are not standardized. Nevertheless, the correlation between the Kogut-Singh and the Euclidean versions of this index is .95 (see Table 1). The ICRG consists of 12 dimensions related to government and political stability, levels of socio-economic development, conflict and corruption, and religious and ethnic tensions. As shown in Table 1, the Kogut and Singh index using ICRG dimensions correlates .96 with the Euclidean version.

The need to re-scale and correct for the variance differences between the dimensions included in a distance index depends on the data used. Both for cultural and institutional distance, re-scaling matters little. For the QoG-based institutional distance index, it does not matter at all. The high correlations between distance indices applying variance correction or not (Kogut-Singh vs. Euclidean) have implications for the interpretation of the results of distance studies. Given these high correlations, we would not expect results to differ substantially between studies using these two methods (all else being equal).

However, one important clarification needs to be made. It is not always clear whether researchers use the variance of a dimension that is available for all country data, or the variance within a dataset that consists of only a subsample of countries (e.g., only European countries or only dyads between Germany and any other country). For Table 1, we have used the variance as based on all available countries. Obviously, the choice of what variance to use can have a significant influence on the final distance index. From a theoretical perspective, we think it would be best to correct for the variance that is considered relevant for the firms under consideration. In most cases, however, we do not know the actual country exposure of a firm (either because we do not know the portfolio of countries in which a firm has invested, or because we do not know the countries the firm has possibly considered for a location choice decision), and it may thus be most practical to use the variance of all available data. We would urge authors to be transparent in this regard.

\section{Recommendation}

For the cultural and institutional distances that we computed, rescaling only has a small impact on the resulting index. For these indices, it does not matter much whether we use the Kogut and Singh index or the Euclidean distance index. Yet, this could be different for other types of distance. We generally recommend that researchers re-scale individual dimensions of distance - especially when there are substantial differences in variance across dimensions - and that they are transparent about which variance is used when doing so.

\section{Taking Care of Co-variance}

In addition to the need to correct for variance differences across dimensions, a second concern with Euclidean approaches is that they disregard potential correlations between the individual distance dimensions. Shenkar (2001) pointed out that correlated dimensions may exert an undue influence on the final index. The most frequently used methods to correct for co-variance across distance dimensions is the Mahalanobis index (Mahalanobis, 1937). The popularity of this method has grown since Berry et al. (2010) introduced it to the international business field. 
Table 1 Pairwise correlation between Kogut-Singh index $(K S I)$ and Euclidean distance (ED)

\begin{tabular}{llccr}
\hline Distance construct & Database & $\begin{array}{c}\text { Correlation between KSI and } \\
\text { ED }\end{array}$ & $\begin{array}{c}\text { Number of country } \\
\text { pairs }\end{array}$ & $\begin{array}{c}\text { Number of } \\
\text { countries }\end{array}$ \\
\hline Cultural distance & & Hofstede 4 dimensions & .96 & 4830 \\
& Hofstede 6 dimensions & .97 & 3782 & 70 \\
& Schwartz & .94 & 4970 & 71 \\
Institutional & Globe-values & Quality of Governance (QoG) & .89 & 3306 \\
distance & Economic Freedom Index (EFI) & 1.00 & 38,612 & 197 \\
& International Country Risk Guide & .95 & 28,390 & 169 \\
& (ICRG) & .96 & 19,182 & 139 \\
\hline
\end{tabular}

Pairwise correlations between the Kogut and Singh index (Eq. 1) and the Euclidean distance (Eq. 2) for different distance constructs. For QoG, EFI, and ICRG, we used the 2013 scores. Correlations are based on unique country pairs (home-home combinations are excluded).

The Mahalanobis approach takes the full variance-co-variance matrix into account when computing distance between country pairs. As Berry et al. (2010) note, Mahalanobis' technique is especially interesting when the dimensions included in the distance index are measured on a different scale (e.g., GDP per capita and inflation rates). This argument is less relevant to cultural and institutional distance because both are commonly measured using similarly scaled dimensions (e.g., the Hofstede dimensions and the EFI dimensions are measured on a 0-100 scale, and the QoG dimensions are standardized).

The Mahalanobis distance is frequently misunderstood, perhaps because the technique itself is relatively complex. Often, Mahalanobis distance is perceived to be the most advanced or the best technique to create a composite index (Flury \& Riedwyl, 1986), but this is not necessarily true (Brereton \& Lloyd, 2016). When the individual distance dimensions included in the index are totally uncorrelated, the resulting Mahalanobis index is perfectly correlated with a variance-corrected Euclidean index (De Maesschalck, JouanRimbaud, \& Massart, 2000). In this case, applying a Mahalanobis technique and correcting for the covariance does not add value.

The Mahalanobis index also has no added value when all the dimensions are very highly correlated with each other (Brereton \& Lloyd, 2016). For example, the correlations between the six QoG indicators range between .62 and $.94 .{ }^{11}$ A principal component factor analysis on these six indicators shows that they reflect one single construct explaining $86 \%$ of the variation across the six indicators. Given these very high correlations, it makes sense to use the factor score and to measure institutional quality as one single reflective construct (e.g., Lavie \& Miller, 2008; Zaheer \& Hernandez, 2011; Klopf \& Nell, 2018).

Thus, Mahalanobis' technique becomes relevant when there is a mix of high and low correlations between the indicators included. Under these circumstances, it may - albeit not necessarily - yield quite different results as compared to Euclidean approaches.

The six Hofstede dimensions, as well as the Schwartz and Globe dimensions, show such a mix of correlations (see "Appendix B"). While the QoG indicators are highly correlated, this does not hold for the $10 \mathrm{EFI}$ dimensions (range between .01 and .92) and the 12 ICRG dimensions (range between .02 and .80 ) (see "Appendix C"). Table 2 compares the (variance-corrected) Euclidean distance index with the Mahalanobis distance index for cultural and institutional distance using alternative databases.

The Euclidean (four dimensional) Hofstede-based cultural distance correlates .88 with the Mahalanobis Hofstede-based cultural distance. For Hofstede's six-dimensional model, this correlation is .84. Using alternative culture frameworks, we find that the correlation between the Euclidean distance and the Mahalanobis distance drops to .58 (Schwartz) and .72 (Globe). For the EFI-based institutional distance index, we find a correlation of .62, and for ICRG this correlation is .58.

Table 3 shows the correlations between QoGbased institutional distance constructs using Euclidean, Mahalanobis, and factor score techniques. The correlation between the Euclidean and Mahalanobis construct is only .40. The correlation between the Euclidean and the factor score using the first principal component of all six QoG indicators is .97 .

The discussion on co-variance correction relates to the literature on index construction methods, 
and the distinction between formative and reflective constructs (Bollen \& Diamantopoulos, 2017; Coltman, Devinney, Midgley \& Venaik, 2008; Diamantopoulos, Riefler \& Roth, 2008; Diamantopoulos \& Winklhofer, 2001). Starting with the Kogut and Singh index (1988), cultural distance has been treated as a formative construct based on the four individual dimensions. The Mahalanobis approach continues this tradition as it essentially represents a formative approach to index construction. QoG, however, has been interpreted more as a reflective construct, whereby the latent institutional distance variable is reflected by all the individual dimensions (Lavie \& Miller, 2008; Zaheer \& Hernandez, 2011; Klopf \& Nell, 2018; Slangen \& Beugelsdijk, 2010).

We do not argue here that correcting for covariance by using Mahalanobis' approach is wrong. However, researchers should be aware that it represents a formative approach based on a given number of dimensions. It is debatable whether cultural distance and other distance constructs are theoretically of a formative nature or a reflective nature, or whether there is a more complex factor structure where both formative and reflective aspects are present. We think that highly aggregated constructs, such as distance constructs, often possess characteristics of reflective as well as formative constructs, a common phenomenon in the field of index construction (Bollen \& Diamantopoulos, 2017), but which has been neglected in most distance research. In fact, the six cultural dimensions developed by Hofstede are already based on a factor analytic procedure, using the original survey questions based on a reflective logic. The Hofstede-based Mahalanobis distance index thus already represents a complex factor structure with formative and reflective elements.

The relatively high correlations between the Hofstede indices, whether or not applying covariance correction, have implications for the interpretation of results of distance studies. Given these high correlations, we would not expect results to differ substantially between studies using these two methods (all else equal). In fact, meta-analysis of cultural distance and its relation to firm performance shows that there is no significant difference between the results obtained with the Hofstedebased Kogut and Singh index or with its Mahalanobis equivalent (Beugelsdijk et al., 2018). Yet, we do not know whether this result can be generalized to other cultural or institutional distance indices.
The correlations shown in Tables 2 and 3 give reason for concern.

\section{Recommendation}

We think that Mahalanobis' approach is valuable for correcting potential co-variance between the dimensions. Our analysis of the three most used cultural and institutional distance indices shows that co-variance correction matters, but need not yield radically different distance indices. In the case of Hofstede-based cultural distance, using Mahalanobis' approach does not fundamentally alter the index as compared to a Euclidean approach and can therefore safely be ignored. For the other distance measures used here, co-variance correction matters more and should thus be carefully examined. We recommend that scholars be transparent about their approach to co-variance correction. We also think that more research is needed on leveraging different, more complex index construction methods using structural equation modeling techniques, and that researchers should explain more clearly whether they want to treat distance as a formative or a reflective construct.

\section{DATA SELECTION CHALLENGES FOR BUILDING A DISTANCE INDEX}

We now turn to two data-related questions. First, how does one add a dimension to an already existing multidimensional framework? For instance, Hofstede et al. (2010) added two dimensions to the original four of the framework. Second, how does one handle alternative, competing databases to operationalize cultural or institutional distance? As discussed earlier, alongside Hofstede $(1980,2001)$, the Schwartz $(1994,1999,2006)$ and Globe databases (House et al., 2004) provide country scores on a set of cultural dimensions. All three frameworks measure cultural variation across countries. Similarly, institutional distance has been measured using the QoG, EFI and ICRG databases, which all measure variation in institutional quality across countries.

All these frameworks provide country measures of cultural dimensions or institutional quality. Should they be treated as substitutes such that a cultural or an institutional distance index based on Hofstede or QoG data can be used as a robustness test for a cultural or an institutional distance index, based on Schwartz/Globe or ICRG/EFI data, respectively? If the frameworks cannot be considered substitutes, how does one support the choice of a 
Table 2 Pairwise correlation between Euclidean distance $(E D)$ and Mahalanobis distance (MD)

\begin{tabular}{llccr}
\hline $\begin{array}{l}\text { Distance } \\
\text { construct }\end{array}$ & Database & $\begin{array}{c}\text { Correlation between ED and } \\
\text { MD }\end{array}$ & $\begin{array}{c}\text { Number of country } \\
\text { pairs }\end{array}$ & $\begin{array}{c}\text { Number of } \\
\text { countries }\end{array}$ \\
\hline Cultural distance & Hofstede 4 dimensions & .88 & 4830 \\
& Hofstede 6 dimensions & .84 & 3782 & 70 \\
& Schwartz & .61 & 4970 & 62 \\
Institutional & Globe-values & .73 & 3306 & 71 \\
distance & Economic Freedom Index (EFI) & .62 & 28,390 & 169 \\
& International Country Risk Guide & .58 & 19,182 & 139 \\
\hline
\end{tabular}

Pairwise correlations between Euclidean distance and Mahalanobis distance for different constructs. The Euclidean distance is variance corrected. For EFI and ICRG, we use the 2013 scores. Correlations are based on unique country pairs (home-home combinations are excluded).

Table 3 Pairwise correlation between Euclidean distance $(E D)$, Mahalanobis Distance $(M D)$, and distance on first principal component of QoG indicators

\begin{tabular}{llcc}
\hline $\begin{array}{l}\text { Distance } \\
\text { construct }\end{array}$ & Database & $\begin{array}{c}\text { Correlation between ED } \\
\text { and MD }\end{array}$ & $\begin{array}{c}\text { Correlation between ED and distance on first principal } \\
\text { component }\end{array}$ \\
\hline $\begin{array}{l}\text { Institutional } \\
\text { distance }\end{array}$ & $\begin{array}{l}\text { Quality of Governance } \\
\text { (QoG) }\end{array}$ & .40 & .97 \\
\hline
\end{tabular}

Euclidean distance is variance-corrected. We use the 2013 scores for QoG. Correlations are based on unique country pairs (home-home combinations are excluded). Number of countries is 197.

specific one? If two frameworks provide country scores for the same conceptual dimension but in slightly different ways, can they (or should they) be combined to generate one composite distance index? We address these practical questions below.

\section{Additional Dimensions}

Some composite distance constructs, such as the six-dimensional institutional distance index based on the QoG indicators, have been based on the same set of six dimensions since their inception. Moreover, as noted above, the six QoG indicators are so highly correlated that leaving one out would not have a significant impact on the index. ${ }^{12}$ This is not necessarily the case for other databases, and that includes the most often used cultural distance index based on Hofstede's data.

Hofstede and co-authors have added "Long term orientation" and "Indulgence versus restraint" to the original four dimensions (Hofstede et al., 2010). The first four dimensions are based on data collected from 1968 to 1972, while the additional two use more recent data from the 2000s. Long-term orientation and indulgence versus restraint are moderately correlated $(r=-.43)$, and not highly correlated with the original four dimensions (see "Appendix B"). This raises the question of whether the six-dimensional index is preferable to the four- dimensional one, and whether adding two dimensions makes a difference. The correlation between the (Mahalanobis) four- and six-dimensional constructs is high at .81 (it is .82 using the Euclidean distance), so adding the two new dimensions has little impact.

Although the high correlations between the fourand six-dimensional Hofstede frameworks suggests that adding dimensions is not very likely to yield radically different results, it does raise the more fundamental question of whether adding these two dimensions is theoretically and methodologically sound in the first place. Hofstede's four-dimensional framework has been fiercely criticized, with detractors questioning the representativeness of his sample, the face validity of the questions, the labeling of the dimensions, the treatment of individualism and power distance as two separate dimensions, and the usefulness of a framework developed more than 40 years ago (see, e.g., Ailon, 2008; Baskerville, 2003; Brewer \& Venaik, 2011;McSweeney, 2002, 2009; Smith, Dugan, \& Trompenaars, 1996; Oyserman, Coon, \& Kemmelmeier, 2002).

In our view, whether these additions make sense depends to a large extent on whether one considers the framework in its totality (i.e., a set of cultural dimensions shaping behavior), or whether one is 
interested in cross-country distance indices. When considering the former, one should take into account that the first four dimensions are based on survey data different from those used for the two additional dimensions. Hofstede did not use the methodology one would use today to develop cultural dimensions, nor follow item selection procedures, nor apply factor analysis to all items associated with all six dimensions. Unfortunately, it is not possible to go back and do this today, as the original raw data are no longer available. ${ }^{13}$ Importantly, a factor analysis on the six dimensions (not the underlying items) yields three factors (see "Appendix D"). Had Hofstede used factor analysis on both IBM and WVS questions, it is highly unlikely that he would have settled on a sixdimensional framework.

From a distance perspective, however, some of the critical comments raised against Hofstede (and also against Schwartz and Globe) need not be problematic because they are not really relevant. For example, the discussion of whether the labels reflect the underlying items matters when giving substantive meaning to specific dimensions, which is not the case when all dimensions are collapsed into a cultural distance index (but, of course, labels do matter when theorizing on the distance on a specific cultural dimension). Similarly, while cultural indicator levels can change, this may not affect cultural distance. Cultures change, but the available evidence suggests that many countries tend to move in the same direction towards becoming more individualistic, less power distant, and more indulgent and emancipative (Beugelsdijk \& Welzel, 2018; Fernandez, Carlson, Stepina, \& Nicholson, 1997; Inglehart, 1997; Ingehart \& Baker, 2000; Inglehart \& Welzel, 2005). ${ }^{14}$ This leaves the cultural distance between countries relatively constant. Hence, 1970s' culture scores would no longer be representative when used in terms of absolute levels, but they may still be useful as input in a cultural distance index (Beugelsdijk et al., 2015; Beugelsdijk \& Welzel, 2018).

Finally, whether a particular culture framework is useful also depends on whether it is deployed as an integrated and internally consistent set of cultural dimensions to analyze, explain, and predict how particular cultural values affect specific outcomes, or whether the dimensions associated with a framework are used as input in a cultural distance index. When reflecting on the Hofstede's framework, the correlated nature of the additional dimensions may be somewhat problematic when looking at the framework in its totality, but the addition of two dimensions is less problematic from a distance perspective, given the correlation of .8 between the four- and six-dimensional frameworks.

\section{Recommendation}

Assuming that the research question addressed calls for a composite index, as opposed to an individual distance dimension (e.g., the difference in uncertainty avoidance or difference in corruption levels), we suggest following Shenkar (2001), in that researchers should take all readily available information into account. For cultural distance and the Hofstede framework, this would imply that the sixdimensional framework is preferred as compared to the four-dimensional one, with the important caveat that users of the six-dimensional framework need to be aware of its theoretical and methodological characteristics, such as its sampling procedures, theoretical grounding, factor analytic structure, and the relationship between questionnaire items and the labeling of the dimensions.

\section{Alternative Frameworks}

As noted above, scholars have a choice between Hofstede, Schwartz and Globe for cultural distance. In addition, Berry et al. (2010) and Beugelsdijk et al. (2015) have used WVS-EVS data to develop Hofstede-inspired cultural dimensions. To measure institutional distance, scholars have mostly used the World Bank QoG data, the Heritage Foundation EFI or the ICRG scores from the PRS group. In many studies, the preference for one of these frameworks has not been properly explained. Frequently, reference is just made to prior studies using a particular framework. The risk of not specifying explicitly why a particular framework and associated data are most suitable for a specific distance study is that it allows for $p$-hacking (Meyer, van Witteloostuijn, \& Beugelsdijk, 2017). Furthermore, the choice of framework matters dramatically. In Table 4, we compare Mahalanobis distance indices using alternative data sources.

In the case of cultural distance, the various frameworks generate very different indices. The index based on all six Hofstede dimensions correlates at .01 with the Schwartz-based index, and at .11 with the Globe-based index. Schwartz and Globe only correlate at .18. The (very) low correlations between these three well-known cultural frameworks extend to the WVS-EVS based cultural distance indices as developed by Berry et al. (2010) and Beugelsdijk et al. (2015). ${ }^{15}$ 
Figure 1 visualizes the relationship between a Hofstede-based and a Schwartz-based cultural distance index using Mahalanobis' technique, with the United States as the home country. If both distance indices resulted in the same scores, the correlation would be 1 and all observations in Fig. 1 would lie on the $45^{\circ}$ diagonal. This is clearly not the case and the shared variance is close to zero. Comparisons between Hofstede and Globe, and Schwartz and Globe yield similar pictures. Thus, cultural distance scores depend to a large extent on the culture framework used.

Figure 2 visualizes the relationship between an EFI-based and ICRG-based institutional distance index (using Mahalanobis' technique and again with the United States as the home country). The correlation across all country pairs in the world is .27 (.34 for the United States as the home country). Although these correlations are higher than in the case of alternative cultural distance indices, they can still be considered low. Thus, institutional distance scores also depend on the data used.

These low correlations between the Hofstede, Schwartz, and Globe-based cultural distance indices (as well as the WVS-EVS-based extensions) and the EFI- and ICRG-based institutional distance indices essentially mean that these indices capture different facets of culture and institutions. ${ }^{16}$ This raises the questions of whether one index is preferable to the other, and why. It also has implications for how to interpret and compare studies which use alternative indices. If there are major differences between two indices supposedly measuring the same construct, results from different operationalizations cannot be compared in a simple fashion, thereby calling for more thoughtful reflection.

\section{Recommendation}

There are three options to address the choice among alternative frameworks. We illustrate these options in the context of cultural distance, but our reasoning can also be applied to institutional distance.

The first option is to select one of the cultural frameworks and to provide a theoretical and/or methodological justification for its use. It goes beyond the scope of this editorial to discuss all the theoretical and methodological pros and cons of the three frameworks. As Schwartz notes when comparing his framework with Hofstede's, his "dimensions are based on different theoretical reasoning, different methods, a different set of nations, different type of respondents, data from a later historical period, a more comprehensive set of values, and value items screened to be reasonably equivalent in meaning across cultures" (Schwartz, 1994: $116-117) .{ }^{17}$ We refer to the original studies as well as discussions in cross-cultural psychology comparing these frameworks (Bond, 2002; Hofstede, 2010; Oyserman et al., 2002; Matsumoto \& Yoo, 2006; Peterson, 2003, 2004; Peterson \& Castro, 2006; Peterson \& Søndergaard, 2011; Ralston et al., 2011, 2014; Schwartz, 2014; Smith, 2006; Smith et al., 1996).

However, as we argued before, not all of the criticism raised against these frameworks is relevant when cultural distance is concerned. For example, if Inglehart's thesis is correct, and cultures change but countries continue to move in the same direction, then it does not make sense, for example, to choose Globe over Hofstede because Globe data are more recent. Explicitly specifying why a particular framework is used is important, because the choice of framework is likely to affect empirical results (Beugelsdijk et al., 2018). Such explanations and justifications will improve the quality of the debate between authors and reviewers.

The second option is to argue, on theoretical and methodological grounds, that none of the differences between the three frameworks allow for a clear reason why one should be preferred over another. In this case, one might be indifferent regarding which framework to use. In addition, one could argue that all three frameworks capture part of the overall variation in cultural values and all three do so in an imperfect way. Hofstede's data give information on cultural diversity in a matched sample of IBM employees (complemented by two dimensions based on stratified representative samples). Schwartz provides similar information coming from students and teachers, while Globe does so coming from middle managers. While the frameworks partly overlap, as evidenced by the correlations between the dimensions, combined, the three sets of data arguably pick up more variation in cross-country cultural differences than when used in isolation (Steenkamp, 2001). Therefore, one could argue that integrating Hofstede, Schwartz, and Globe in one overall distance index may provide a more complete picture of the overall variation in cultural values (Beugelsdijk, Kostova \& Roth, 2017). From such an "agnostic" perspective, 
Table 4 Pairwise correlations between different cultural distance indices (Mahalanobis corrected)

\begin{tabular}{lllll}
\hline & & 1 & 2 & 3 \\
\hline 1 & Cultural distance Hofstede 6 & 1 & & \\
2 & Cultural distance Schwartz & .01 & 1 & .18 \\
3 & Cultural distance Globe & .11 & .11 & .13 \\
5 & Cultural distance WVS-EVS Berry et al. & .16 & .24 & .32 \\
\hline
\end{tabular}

Correlations are based on unique country pairs (home-home combinations are excluded). The WVS-EVS used in Berry et al. (2010) are available for 96 countries. The WVS-EVS data used in Beugelsdijk et al. (2015) are available for 86 countries.

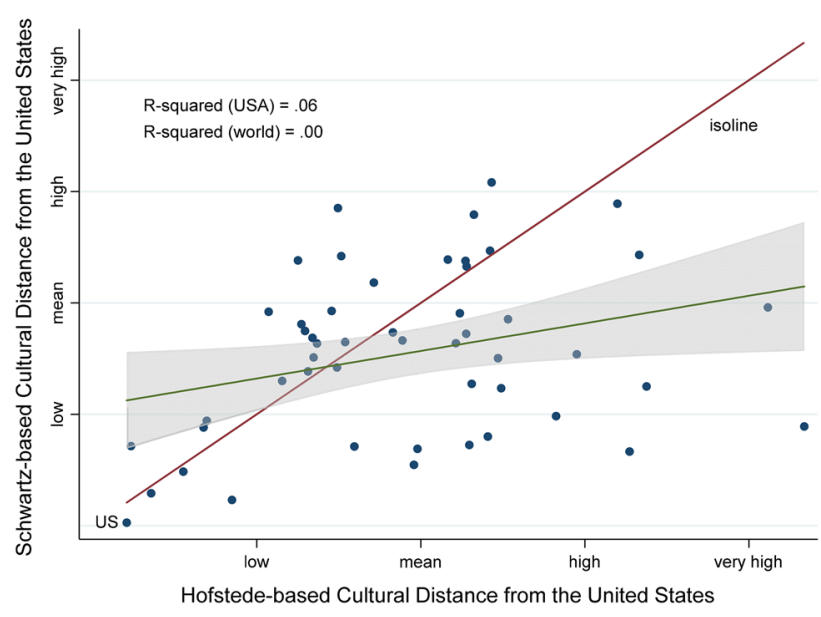

Figure 1 Comparing Hofstede- and Schwartz-based cultural distance scores; cultural distance is computed using Mahalanobis' technique and scores are standardized to facilitate comparison. The gray area is the $95 \%$ confidence interval around the regression line. The United States is the home country.

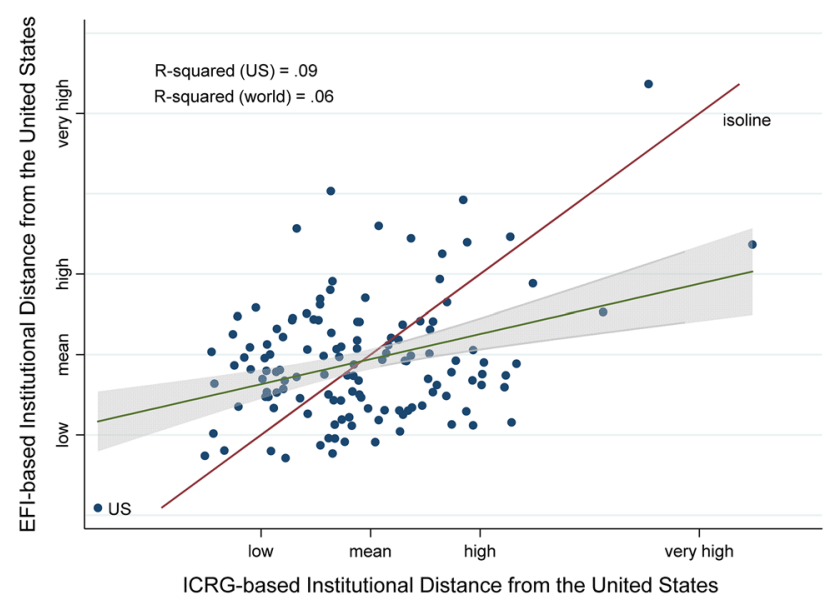

Figure 2 Comparing ICRG- and EFI-based institutional distance scores; institutional distance is computed using Mahalanobis' technique and scores are standardized to facilitate comparison. The gray area is the $95 \%$ confidence interval around the regression line. The United States is the home country. all 22 indicators for cultural differences (six dimensions from Hofstede, seven from Schwartz, and nine from Globe) are indicative of cultural values, and the Mahalanobis technique can be used to integrate them in one overall index. The resulting "grand" cultural distance index correlates .25 with Hofstede's, .36 with Schwartz', and .51 with Globe's cultural distance indices. One practical disadvantage is that data for a combined "grand" index are only available for 40 countries. More work needs to be carried out to explore the usefulness, as well as the conceptual and methodological soundness, of such a "grand" index approach.

The third option is simply not to use a cultural distance index. All three frameworks have serious theoretical and methodological drawbacks, which have led some scholars to recommend that they should be avoided (McSweeney, 2002; Kirkman et al., 2006). The low correlations between the cultural distance indices built upon Hofstede, Schwartz and Globe suggest that the three indices capture very different aspects of the overall variation in cultural values, but this result can also be interpreted as evidence of their lack of conceptual and methodological soundness.

This third option still allows controlling for cultural differences in empirical studies. If the variation in cultural distance is related to the variation in other - less disputed - distance dimensions, we could perhaps indirectly control for cultural distance by including those alternative distance dimensions. For example, we know that economic development affects cultural values (Beugelsdijk \& Welzel, 2018; Inglehart \& Baker, 2000), meaning that the inclusion of economic distance as a control variable in empirical studies is likely to capture a substantial part of the impact of cultural distance. ${ }^{18}$ Empirical research leveraging index construction methods referred to earlier is required to further unpack the empirical 
relationship between cultural distance and other distance dimensions.

\section{CONCLUSION}

In this editorial, we have discussed a set of recurring questions on the theory, methods and data utilized in cross-country distance research. We have pointed to commonalities in distance indicators and have formulated best practice guidelines on: (1) how to theorize on distance, and (2) what method and (3) what data to use when constructing a distance index. We have illustrated each of these topics with data on as many country pairs as possible. Our goal is to help authors, reviewers, and editors focus on what matters most in terms of theory, method, and data by clarifying the issues most critical to improving distance research. At the same time, we acknowledge that there are some considerations that simply require more transparency so that the nature of the models and relationships tested become clearer. Above all, we call for a more disciplined approach in distance research that is based on a better understanding of what has already been achieved in the field and what still remains to be done.

We reach three main conclusions, which collectively highlight the need to match data and method with the nature of an explicitly and carefully crafted theoretical argument. First, there is no distance theory as such. Distance is given meaning within the context of specific theoretical frameworks. Hence, it is critical that authors specify clearly the theoretical context of their arguments on distance. It is important to be explicit and precise about the exact mechanisms by which distance affects a particular outcome - especially because many decisions in international business are multi-staged. Credibly articulating assumptions and mechanisms should clarify the nature of the relationship between distance and, for example, location choice, entry mode decisions, and performance. Theoretical clarity is also required when distance is conceptualized as an aggregate construct, which requires a composite index.

Second, using three different cultural frameworks (Hofstede, Schwartz and Globe) and three different sets of indicators of institutional quality (Quality of Governance, Economic Freedom Index, and International Country Risk Guide), we have demonstrated that the choice of method can, but need not, have a major impact on the results. Scholars need to be transparent about the method employed, and ideally use the (co-)variance-corrected distance. Although the Mahalanobis technique to control for (co-)variance is very powerful, the exact way to control for co-variance is related to the theoretical nature of the construct (formativereflective), an aspect of distance research that has so far not been sufficiently addressed in the distance literature.

Third, in contrast to the relatively minor implications of correcting for (co-)variance, the selection of the framework and the data to measure cultural or institutional distance has a major impact. The Hofstede-based cultural distance framework measures different aspects of cross-cultural distance compared with the frameworks of Schwartz or Globe. Authors should properly justify their choice of framework. It is important to note, however, that some of the criticism directed towards cultural frameworks does not apply to composite distance constructs. For institutional distance, the choice of data also matters, but the difference between what QoG and EFI measure is smaller than in the case of cultural distance.

Our discussion of distance is not without limitations. First, we have not addressed the stability of the effect of distance on a particular outcome variable. If firms learn how to deal with contextual differences, their effect should become smaller over time, even though the distance itself stays the same. Yet the seven meta-analyses on the impact of cultural distance effects show no consistent evidence of its reduced impact over time (Beugelsdijk et al., 2018; Magnusson, Baack, Zdravkovic, Staub, \& Amine, 2008; Morschett et al., 2010; Stahl \& Voigt, 2008; Tihanyi, Griffith, \& Russell, 2005; Zhao, Luo \& Suh, 2004). The lack of evidence of a temporal effect of cultural distance contrasts with firm-level studies showing that firms can learn to deal with cross-country differences (Johanson \& Vahlne, 2009). Addressing the temporal stability of the effect of distance on international business outcomes would be a fruitful avenue for further research (Friedman, 2005; Ghemawat, 2017).

Second, in samples of only one home or one host country, distance effects are conflated with level effects (Brouthers et al., 2016; Harzing \& Pudelko, 2016; Van Hoorn \& Maseland, 2016; Sivakumar \& Nakata, 2001). In such a sample structure, there can be a high negative or positive correlation between 
the distance from a home country to other countries and the level score of the construct on which the distance is calculated. For example, the QoGbased institutional distance between the United States and all 196 host countries for which we have data correlates -.97 with the institutional quality in these host countries. The reverse obtains for poor home countries, with the correlation being +.98 for Zimbabwe. These high correlations for extreme countries (United States on the one hand and Zimbabwe on the other) illustrate that studies with single home or host countries cannot disentangle distance from country-level effects. Clearly, distance effects can be asymmetric. All the correlations we have reported are based on all home and host countries for which data are available. We do so to make sure that our conclusions are not affected by this conflation of distance and level effects. In addition to using multiple home and host countries, as recommended by Brouthers et al. (2016), we suggest that scholars report the correlation between the distance variable and the host country-level score of the variable for which distance is calculated. A high correlation is reason for concern, as it affects the interpretation of the distance argument tested.

Lastly, we have argued that there is no grand theory of distance, and that distance only has meaning within the context of a specific theory. Here, researchers should carefully reflect about the spatial mechanisms relevant to the research question they try to address. From a conceptual perspective, continuous distance effects can be found at all spatial levels, both within and between countries (Dheer, Lenartowicz, \& Peterson, 2015; Lenartowicz \& Roth, 2001), while national border effects only occur between countries. Unlike distance effects, border effects are discrete because borders often serve as a qualitative disjuncture in space (Anderson, 1991; Beugelsdijk \& Mudambi, 2013), and because many contextual characteristics are nation-specific (this holds especially for formal institutions) (Peterson, Søndergaard, \& Kara, 2018). Here, we see an exciting research agenda unfolding on cross-country distance and on the rising meaning of national borders in the face of anti-globalization movements.

\section{ACKNOWLEDGEMENTS}

We thank Heather Berry, Johannes Kleinhempel, Thomas Lindner, Laura Spierdijk, Alain Verbeke, Tom
Wansbeek, Juliette de Wit, participants of the AIB 2018 professional development workshop, and our anonymous reviewers, for comments and suggestions.

\section{NOTES}

${ }^{1}$ In one of the earlier explanations of this notion, Goodnow and Hansz (1972) state that, as firms enter markets further away from the United States, "government becomes less stable, the markets become poorer, the economy becomes less stable, cultural homogeneity declines, legal and geographical barriers go up and cultures become different" (1972: 37). Johanson and Vahlne (1977) generalize this argument by stating that the further from the home country, the more uncertainty and the higher the costs of acquiring information.

${ }^{2}$ It is interesting to note that trade, the dependent variable in gravity models, is one of the explanatory variables in the Uppsala model.

${ }^{3}$ There is no grand theory in the sense of a single framework with a set of assumptions, mechanisms, and boundary conditions. That does not mean that there is no theory of national cultural differences (Adler, 1983).

${ }^{4}$ Theoretically, such discrete changes can also be found at other levels. For example, Ronen \& Shenkar (2013) have shown that countries can be grouped into a limited number of culturally homogeneous supra-national zones.

${ }^{5}$ In light of the popularity of their distance measure, it is interesting to point out that Kogut \& Singh's (1988) findings regarding the effect of uncertainty avoidance on entry mode were stronger than the cultural distance effect (see Kogut \& Singh, 1988: 424).

${ }^{6}$ Occasionally, this is referred to as Cartesian distance (e.g., Buchner, Espenlaub, Khurshed \& Mohammed, 2017).

${ }^{7}$ In addition to the Kogut and Singh index and the Euclidean index, some researchers have used a mix of the two. For example, Barkema \& Vermeulen (1997) use an Euclidean distance index but correct for differences in the variances of each of Hofstede's cultural dimension by multiplying the individual dimension distances by $1 / v_{i}$, where $v_{i}$ is the variance of each cultural dimension. The Kogut and Singh index adapts the scales in a similar way (see Eq. 1), but does not take the square root. In this case, the difference between the Kogut and Singh index and this third approach is the aggregation procedure (square root vs. dividing by the number 
of dimensions). Although this is not the same type of transformation, they are effectively highly correlated.

${ }^{8}$ In the case of South Africa, the WVS-EVS data provide a score for the fifth and sixth dimensions of Hofstede's framework. The four original Hofstede dimensions refer to Caucasian South Africans only. We have decided not to mix both samples, and hence exclude South Africa from the analysis.

${ }^{9}$ Inglehart (1997) used the WVS-EVS data to develop two dimensions of differences in national cultural values related to degree of materialism. However, his framework is rarely used in management (it is mostly used in sociology and political science). One reason for the limited use of the WVS-EVS data in management is the fact that, despite the use of stratified nationally representative samples and the richness of the WVS-EVS data (they contain more than 200 value-related questions), the user-friendliness of the database is limited. Note also that in its fifth and sixth rounds, the WVS has included a condensed ten-item version of the Schwartz values.

${ }^{10}$ These correlations do not depend on the choice of home country. Drogendijk \& Slangen (2006: 372 ) report a correlation of .97 between the Euclidean and Kogut and Singh versions of the four-dimensional Hofstede index when using the Netherlands as a home country. For the most used home country in cultural distance research, the United States, this correlation is also .97.

${ }^{11}$ We use data for 2013, but as the QoG index is highly correlated over time (.99 between $t$ and $t+1)$, the selected year does not affect the outcome.

${ }^{12}$ The Mahalanobis institutional distance based on six dimensions correlates .96 with the fivedimensional Mahalanobis institutional distance index (using QoG data).

${ }^{13}$ As the European manager of personnel research at IBM, Geert Hofstede had privileged access to the confidential IBM employee data used to develop his cross-cultural framework. The original data stayed at IBM after Geert Hofstede left IBM in 1973 (based on personal communication from Geert Hofstede).

${ }^{14}$ See Ralston, Holt, Terpstra, \& Kai-Cheng (1997) and Ralston (2008) for an alternative view.
${ }^{15}$ Although both Berry and Beugelsdijk use WVSEVS to develop Hofstede-inspired cultural dimensions, there is only limited overlap in the WVS-EVS questions used by Berry et al (2010) and Beugelsdijk et al (2015). Both studies use the question on trust (WVS code a165). The correlations between the original Hofstede dimensions, and the ones developed by Berry et al. (2010) and Beugelsdijk et al. (2015) differ. Berry et al.'s (2010) individualism correlates .24 with Hofstede's original individualism, Berry et al's power distance correlates .25 with Hofstede's, uncertainty avoidance correlates .52 with Hofstede's and Berry et al's masculinity correlates .16 with Hofstede's. For Beugelsdijk et al. (2015), these correlations with the original Hofstede dimensions are: .77 for individualism, .74 for uncertainty avoidance, .72 for power distance, and .92 for indulgence versus restraint.

${ }^{16}$ Note that the correlations shown in Table 3 are country-specific, because each cultural distance is calculated relative to a different home country. Hence, the correlation between two distance indices can vary depending on home country. A similar country specificity holds for the correlation between the ICRG- and EFI-based institutional distance indices. We have calculated all the cultural distance correlations shown in Table 3 as well as the correlation between the ICRG- and EFI-based institutional distance indices for each home country. Calculating the country-specific correlations does not change our overall conclusion.

${ }^{17}$ Schwartz has described the difference between his approach and those of others (i.e., Hofstede) in the following way: "(a) It [the approach] derived the cultural orientations from a priori theorizing rather than post hoc examination of data. (b) It designated a priori the value items that serve as markers for each orientation. (c) It used as measures only items tested for cross-cultural equivalence of meaning. (d) It included a set of items demonstrated to cover the range of values recognized cross-culturally, a step toward ensuring relative comprehensiveness of cultural value dimensions. (e) It specified how the cultural orientations are organized into a coherent system of related dimensions and verified this organization, rather than assuming that orthogonal dimensions best capture cultural reality. (f) It brought empirical evidence 
that the order of national cultures on each of the orientations is robust across different types of samples from each of a large number of nations around the world [and using different instruments]. These distinctive features increase the promise of this approach for future research." (Schwartz, 2004: 73, and reprinted in Schwartz, 2006: 179).

\section{REFERENCES}

Abdi, M., \& Aulakh, P. S. 2012. Do country level institutional frameworks and interfirm governance arrangements substitute or complement in international business relations. Journal of International Business Studies, 43(5): 477-497.

Acemoglu, D., Johnson, S., \& Robinson, J. A. 2005. Chapter 6: Institutions as a fundamental cause of long run growth. In P. Aghion \& S. N. Durlauf (Eds.), Handbook of economic growth (pp. 387-472). Amsterdam: Elsevier Holland.

Adler, N. J. 1983. Cross-cultural management research-The ostrich and the trend. Academy of Management Review, 8(2): 226-232.

Ailon, G. 2008. Mirror, Mirror on the wall: Culture's consequences in a value test of its own design. Academy of Management Review, 33(4): 885-904.

Ambos, B., \& Håkanson, L. 2014. The concept of distance in international management research. Journal of International Management, 20(1): 1-7.

Anderson, B. 1991. Imagined communities. London: Verso.

Anderson, J., \& van Wincoop, E. 2003. Gravity with gravitas: A solution to the border puzzle. American Economic Review, 93: 17-192.

Ang, S. H., Benischke, M. H., \& Doh, J. P. 2015. The interactions of institutions on foreign market entry mode. Strategic Management Journal, 36(10): 1536-1553.

Barkema, H. G., \& Vermeulen, F. 1997. What differences in cultural backgrounds of partners are detrimental for international joint ventures? Journal of International Business Studies, 28(4): 854-864.

Baskerville, R. F. 2003. Hofstede never studied culture. Accounting, Organizations and Society, 28: 1-14.

Beckerman, W. 1956. Distance and the pattern of intraEuropean trade. The Review of Economics and Statistics, 38(1): 31-40.

Bergstrand, J. H. 1985. The gravity equation in international trade: Some micro economic foundations and empirical evidence. The Review of Economics and Statistics, 67(3): 474-481.

Berry, H., Guillen, M., \& Zhou, N. 2010. An institutional approach to cross-national distance. Journal of International Business Studies, 41(9): 1460-1480.

Beugelsdijk, S., Kostova, T., Kunst, V., Spadafora, E., \& van Essen, M. 2018. Cultural distance and firm internationalization. Journal of Management, 44(1): 89-130.

Beugelsdijk, S., Kostova, T., \& Roth, K. 2017a. An overview of Hofstede-inspired country level culture research in international business since 2006. Journal of International Business Studies, 48(1): 30-47.

Beugelsdijk, S., Maseland, R., \& van Hoorn, A. 2015. Are scores on Hofstede's dimension of national culture stable over time? A cohort analysis. Global Strategy Journal, 5(3): 223-240.

Beugelsdijk, S., \& Mudambi, R. 2013. MNEs as border-crossing multi-location enterprises: The role of discontinuities in geographic space. Journal of International Business Studies, 44(5): 413-426.

Beugelsdijk, S., Nell, P., \& Ambos, P. 2017b. When do distance effects become empirically observable? An investigation in the context of headquarters value creation for subsidiaries. Journal of International Management, 23(3): 255-267.
${ }^{18} \mathrm{~A}$ similar relationship exists between institutional distance and economic distance, because high-quality institutions are generally associated with high levels of economic development (Acemoglu, Johnson, \& Robinson, 2005).

Beugelsdijk, S., \& Welzel, C. 2018. Dimensions and dynamics of national culture: Synthesizing Hofstede with Inglehart. Journal of Cross-Cultural Psychology. https://doi.org/10.1177/ 0022022118798505.

Bollen, K. A., \& Diamantopoulos, A. 2017. In defense of causalformative indicators: A minority report. Psychological Methods, 22(3): 581-596.

Bond, M. H. 2002. Reclaiming the Individual from Hofstede's ecological analysis - a 20 year odyssey: Comment on Oyserman et al. (2002). Psychological Bulletin, 128(1): 73-77.

Brereton, R. G., \& Lloyd, G. R. 2016. Re-evaluating the role of the Mahalanobis distance measure. Journal of Chemometrics, 30: 134-143.

Brewer, P., \& Venaik, S. 2011. Individualism-collectivism in Hofstede and GLOBE. Journal of International Business Studies, 42(3): 436-445.

Brouthers, K. D. 2002. Institutional, cultural and transaction costs influences on entry mode choice and performance. Journal of International Business Studies, 33(2): 203-221.

Brouthers, L. E., Marshall, V. B., \& Keig, D. L. 2016. Solving the single-country sample problem in cultural distance studies. Journal of International Business Studies, 47(4): 471-479.

Buchner, A., Espenlaub, S., Khurhsed, A., \& Mohammed, A. 2017. Cross-border venture capital investments: The impact of foreignness on returns. Journal of International Business Studies, 49(5): 575-604.

Campbell, J. T., Eden, L., \& Miller, S. 2012. Multinationals and corporate social responsibility on host countries: Does distance matter? Journal of International Business Studies, 43(1): 84-106.

Coltman, T., Devinney, T. M., Midgley, D. F., \& Venaik, S. 2008. Formative versus reflective measurement models: Two applications of formative measurement. Journal of Business Research, 61, 1250-1262.

Cuypers, I.P.R, Ertug, G., Heugens, P.M.A.R, Kogut, B., \& Zou, T. 2018. The making of a construct: lessons from 30 years of the Kogut and Singh cultural distance index. Journal of International Business Studies. https://doi.org/10.1057/ s41267-018-0181-5.

De Maesschalck, R., Jouan-Rimbaud, D., \& Massart, D. L. 2000. The Mahalanobis distance. Chemometrics and Intelligent Laboratory Systems, 50(1): 1-18.

Demirbag, M., Apaydin, M., \& Tatoglu, E. 2011. Survival of Japanese subsidiaries in the Middle East and North Africa. Journal of World Business, 46(4): 411-425.

Dheer, R., Lenartowicz, T., \& Peterson, M. F. 2015. Mapping Indiás regional subcultures: Implications for international management. Journal of International Business Studies, 46(4): 443-444.

Diamantopoulos, A., Riefler, P., \& Roth, K. P. 2008. Advancing formative measurement models. Journal of Business Research, 61(12): 1203-1218.

Diamantopoulos, A., \& Winklhofer, H. M. 2001. Index construction with formative indicators: An alternative to scale development. Journal of Marketing Research, 38(2): 269-277.

Dikova, D., Sahib, P. R., \& van Witteloostuijn, A. 2010. Cross border acquisitions abandonment and completion: The effect of institutional differences and organizational learning in the 
international business service industry, 1981-2001. Journal of International Business Studies, 41(2): 223-245.

Dow, D., \& Karunaratna, A. 2006. Developing a multidimensional instrument to measure psychic distance stimuli. Journal of International Business Studies, 37(5): 1-25.

Drogendijk, R., \& Slangen, A. 2006. Hofstede, Schwartz, or managerial perceptions? The effects of different cultural distance measures on establishment mode choices by multinational enterprises. International Business Review, 15(4): 361-380.

Eden, L., \& Miller, S. R. 2004. Distance matters: Liability of foreignness, institutional distance and ownership strategy. Advances in International Management, 16 (Theories of the Multinational Enterprise: Diversity, Complexity and Relevance), 187-221.

Feenstra, R., Markusen, J., \& Rose, A. K. 2001. Using the gravity equation to differentiate among alternative theories of trade. The Canadian Journal of Economics, 34(2): 430-447.

Fernandez, D. R., Carlson, D. S., Stepina, L. P., \& Nicholson, J. D. 1997. Hofstede's country classification 25 years later. The Journal of Applied Psychology, 137(1): 43-54.

Flury, B. K., \& Riedwyl, H. 1986. Standard distance in univariate and multivariate analysis. American Statistican, 40(3): 249-251.

Friedman, T. L. 2005. The world is flat: A brief history of the twenty-first century. London: Macmillan.

Ghemawat, P. 2001. Distance still matters. The hard reality of global expansion. Harvard Business Review, 79(8): 137-147.

Ghemawat, P. 2017. The laws of globalization and business applications. Cambridge: Cambridge University Press.

Goodnow, J. D., \& Hansz, J. E. 1972. Environmental determinants of overseas market entry strategies. Journal of International Business Studies, 3(1): 33-50.

Gubbi, S. R., Aulakh, P. S., Ray, S., Sarkar, M. B., \& Chittoor, R. 2010. Do international acquisitions by emerging-economy firms create shareholder value? The case of Indian firms. Journal of International Business Studies, 41(3): 397-418.

Guiso, L., Sapienza, P., \& Zingales, L. 2009. Cultural biases in economic exchange. Quarterly Journal of Economics, 124(3): 1095-1131.

Håkanson, L. 2014. The role of psychic distance in international trade: A longitudinal analysis. International Marketing Review, 31(3): 210-236.

Håkanson, L., \& Ambos, B. 2010. The antecedents of psychic distance. Journal of International Management, 16(3): 195-210.

Håkanson, L., Ambos, B., Schuster, A., \& Leicht-Deobald, U. 2016. The psychology of psychic distance: Antecedents of asymmetric perceptions. Journal of World Business, 51(2): 308-318.

Håkanson, L., \& Kappen, P. 2017. The 'casino model' of internationalization: An alternative Uppsala paradigm. Journal of International Business Studies, 48(9): 1103-1113.

Harzing, A. W., \& Pudelko, M. 2016. Do we need to distance ourselves from the distance concept? Why home and host country context might matter more than (cultural) distance. Management International Review, 56(1): 1-34.

He, X., Brouthers, K. E., \& Filatotchev, I. 2013. Resource-based and institutional perspectives on export channel selection and export performance. Journal of Management, 39(1): 27-47.

Hendriks, G., Slangen, A.H.L., \& Heugens, P. M. A. R. 2017. How a firm's domestic footprint and domestic environmental uncertainties jointly shape added cultural distances: The roles of resources dependence and headquarters attention. Journal of Management Studies, 55(6): 883-909.

Hennart, J. F., \& Larimo, J. 1988. The impact of culture on the strategy of multinational enterprises: Does national origin affect ownership decisions? Journal of International Business Studies, 29(3): 515-538.

Hofstede, G. 1980. Culture's consequences: International differences in work-related values. Beverly Hills, CA: Sage.

Hofstede, G. 2001. Culture's consequences; comparing values, behaviors, institutions, and organizations across nations. Thousand Oaks, CA: Sage.
Hofstede, G. 2010. The Globe debate: Back to relevance. Journal of International Business Studies, 41(8): 1339-1346.

Hofstede, G., Hofstede, G. J., \& Minkov, M. 2010. Cultures and organizations: Software of the mind (3rd ed.). McGrawHill: New York.

House, R. J., Hanges, P. J., Javidan, M., Dorfman, P. W., \& Gupta, V. (Eds.). 2004. Culture, leadership, and organizations: The GLOBE study of 62 societies. Thousand Oaks: Sage.

Hutzschenreuter, T., Kleindienst, I., \& Lange, S. 2014. Added psychic distance stimuli and MNE performance Performance effects of added cultural, governance, geographic, and economic distance in $\mathrm{MNEs}^{\prime}$ international expansion. Journal of International Management, 20(1): 38-54.

Hutzschenreuter, T., Voll, J. C., \& Verbeke, A. 2011. The impact of added cultural distance and cultural diversity on international expansion patterns: A Penrosean perspective. Journal of Management Studies, 48(2): 305-329.

Inglehart, R. 1990. Culture shift in advanced industrial society. Princeton, NJ: Princeton University Press.

Inglehart, R. 1997. Modernization and postmodernization: Cultural, economic, and political change in 43 societies. Princeton: Princeton University Press.

Inglehart, R., \& Baker, W. E. 2000. Modernization, cultural change and the persistence of traditional values. American Sociological Review, 65(1): 19-51.

Inglehart, R., \& Welzel, C. 2005. Modernization, cultural change and democracy. New York: Cambridge University Press.

Johanson, J., \& Vahlne, J. E. 1977. The internationalization process of the firm-A model of knowledge development and increasing foreign market commitments. Journal of International Business Studies, 8(1): 23-32.

Johanson, J., \& Vahlne, J. E. 2009. The Uppsala internationalization process model revisited: From liability of foreignness to liability of outsidership. Journal of International Business Studies, 40(9): 1411-1431.

Johanson, J., \& Wiedersheim-Paul, F. 1975. The internalization of the firm: Four Swedish cases. Journal of Management Studies, 12(3): 305-322.

Kaufmann, D., Kraay, A. \& Mastruzzi, M. 2008. Governance matters VII: Aggregate and individual governance indicators 1996-2007. Policy Research Working Paper 4654. The World Bank, Washington DC.

Kirkman, B. L., Lowe, K. B., \& Gibson, C. B. 2006. A quarter century of culture's consequences: A review of empirical research incorporating Hofstede's cultural values framework. Journal of International Business Studies, 37(3): 285-320.

Kirkman, B. L., Lowe, K. B., \& Gibson, C. B. 2017. A retrospective on Culture's Consequences: The 35-year journey. Journal of International Business Studies, 48(1): 12-29.

Klopf, P., \& Nell, P. C. 2018. How "space" and "place" influence subsidiary host country political embeddedness. International Business Review, 27(1): 186-197.

Kogut, B., \& Singh, H. 1988. The effect of national culture on the choice of entry mode. Journal of International Business Studies, 19(3): 411-432.

Kostova, T. 1996. Success of the transnational transfer of organizational practices within multinational companies. Doctoral dissertation, University of Minnesota.

Kostova, T., Nell, P. C., \& Hoenen, A. K. 2017. Understanding agency problems in headquarters-subsidiary relationships in multinational corporations: A contextualized model. Journal of Management, 3(1): 57-81.

Lavie, D., \& Miller, S. R. 2008. Alliance portfolio internationalization and firm performance. Organization Science, 19(4): 623-646.

Lenartowicz, T., \& Roth, K. 2001. Does subculture within a country matter? A cross-culture study of motivational domains and business performance in Brazil. Journal of International Business Studies, 32(2): 305-325.

Li, J., Liu, X., Wright, M., \& Filatotchev, I. 2014. International experience and FDI location choices of Chinese firms: The 
moderating effects of home country government support and host country institutions. Journal of International Business Studies, 45(4): 428-449.

Magnusson, P., Baack, D. W., Zdravkovic, S., Staub, K. M., \& Amine, L. S. 2008. Meta-analysis of cultural differences: Another slice at the apple. International Business Review, 17(5): 520-532.

Mahalanobis, P. C. 1937. Normalisation of statistical variates and the use of rectangular coordinates in the theory of sampling distributions. Sankhya, 3: 35-40.

Makino, S., \& Tsang, E. W. K. 2011. Historical ties and foreign direct investment: An exploratory study. Journal of International Business Studies, 42(4): 545-557.

Malhotra, S., \& Gaur, A. 2014. Spatial geography and control if foreign acquisitions. Journal of International Business Studies, 45(2): 191-210.

Maseland, R., D. Dow, and P. Steel. 2018. The Kogut and Singh national cultural distance index: Time to start using it as a springboard rather than a crutch. Journal of International Business Studies. https://doi.org/10.1057/s41267-018-01833.

Matsumoto, D., \& Yoo, L. H. 2006. Toward a new generation of cross-cultural research. Perspectives in Psychological Science, 1(3): 234-250.

McSweeney, B. 2002. Hofstede's model of national cultural differences and their consequences: A triumph of faith-a failure of analysis. Human Relations, 55: 89-118.

McSweeney, B. 2009. Dynamic diversity: Variety and variation within countries. Organization Studies, 30(9): 933-957.

Meyer, K., van Witteloostuijn, A., \& Beugelsdijk, S. 2017. What's in a $p$ ? Reassessing best practices for conducting and reporting hypothesis-testing research. Journal of International Business Studies, 48(5): 535-551.

Mingo, S., Morales, F., \& Dau, L. 2018. The interplay of national distances and regional networks: private equity investments in emerging markets. Journal of International Business Studies, 49(3): 371-386.

Morschett, D., Schramm-Klein, H., \& Swoboda, B. 2010. Decades of research on market entry modes: What do we really know about external antecedents of entry mode choice? Journal of International Management, 16(1): 60-77.

Nell, P. C., \& Ambos, B. 2013. Parenting advantage in the MNC: An embeddedness perspective on the value added by headquarters. Strategic Management Journal, 34(9): 1086-1103.

Nell, P. C., Kappen, P., \& Laamanen, T. 2017. Reconceptualising hierarchies: The disaggregation and dispersion of headquarters in multinational corporations. Journal of Management Studies, 54(8): 1121-1143.

Oyserman, D., Coon, H. M., \& Kemmelmeier, M. 2002. Rethinking individualism and collectivism: Evaluation of theoretical assumptions and meta-analyses. Psychological Bulletin, 128(1): 3-72.

Peterson, M. 2003. Reviewed work: Culture's consequences: comparing values, behaviors, institutions, and organizations across nations by Geert Hofstede. Administrative Science Quarterly, 48(1): 127-131.

Peterson, M. 2004. Reviewed work: Culture, leadership and organizations: the Globe study of 62 societies. Administrative Science Quarterly, 49(4): 641-647.

Peterson, M., \& Castro, S. L. 2006. Measurement metrics at aggregate levels of analysis: Implications for organizational culture research and the Globe project. The Leadership Quarterly, 17: 506-521.

Peterson, M., \& Søndergaard, M. 2011. Traditions and transitions on quantitative societal culture research in organization studies. Organization Studies, 32(11): 1539-1558.

Peterson, M., Søndergaard, M., \& Kara, A. 2018. Traversing cultural boundaries in IB: The complex relationships between explicit country and implicit cultural group boundaries at multiple levels. Journal of International Business Studies. https:// doi.org/10.1057/s41267-017-0082-z.
Ralston, D. A. 2008. The crossvergence perspective: Reflections and projections. Journal of International Business Studies, 39(1): $27-40$.

Ralston, D. A., Holt, D. H., Terpstra, R. H., \& Kai-Cheng, Y. 1997. The impact of national culture and economic ideology on managerial work values: A study of the United States, Russia, Japan, and China. Journal of International Business Studies, 28(1): 177-208.

Ralston, D. A., et al. 2011. A twenty first century assessment of values across the global workforce. Journal of Business Ethics, 104: 10-31.

Ralston, D. A., et al. 2014. Societal level versus individual level predictions of ethical behavior: A 48-society study of collectivism and individualism. Journal of Business Ethics, 122: 283-306.

Ronen, S., \& Shenkar, O. 2013. Mapping world cultures: Cluster formation, sources and implications. Journal of International Business Studies, 44(9): 867-897.

Salomon, R. 2016. Global vision: How companies can overcome the pitfalls of globalization. Basingstoke: Palgrave MacMillan.

Salomon, R., \& Wu, Z. 2012. Institutional distance and local isomorphism strategy. Journal of International Business Studies, 43(4): 343-367.

Schwartz, S. H. 1994. Beyond individualism/collectivism; new cultural dimensions of values. In U. Kim, H. C. Triandis, C. Kâğitçibasi, S. C. Choi, \& G. Yoon (Eds.), Individualism and collectivism. Theory, method, and applications (pp. 85-119). Thousand Oaks: Sage.

Schwartz, S. H. 1999. Cultural value differences: Some implications for work. Applied Psychology International Review, 48(1): 23-47.

Schwartz, S. H. 2004. Mapping and interpreting cultural differences around the world. In H. Vinken, J. Soeters, \& P. Ester (Eds.), Comparing cultures: Dimensions of culture in a comparative perspective (pp. 43-73). Leiden: Brill.

Schwartz, S. H. 2006. A theory of cultural value orientations: Explication and Applications. Comparative Sociology, 5(2): 137-182.

Schwartz, S. H. 2011. Studying personal values: Personal adventure, future directions. Journal of Cross-Cultural Psychology, 42(2): 307-319.

Schwartz, S. H. 2014. Rethinking the concept and measurement of societal culture in light of empirical findings. Journal of Cross-Cultural Psychology, 45(1): 5-13.

Shenkar, O. 2001. Cultural distance revisited: Towards a more rigorous conceptualization and measurement of cultural differences. Journal of International Business Studies, 32(3): 519-535.

Shenkar, O. 2012. Beyond cultural distance: Switching to a friction lens in the study of cultural differences. Journal of International Business Studies, 43(1): 12-17.

Shenkar, O., Luo, Y., \& Yeheskel, O. 2008. From "distance" to "friction": Substituting metaphors and redirecting intercultural research. Academy of Management Review, 33(4): 905-923.

Sivakumar, K., \& Nakata, C. 2001. The stampede towards Hofstede's framework; Avoiding the sample design pit in cross-cultural research. Journal of International Business Studies, 32(3): 555-574.

Slangen, A. H. L., \& Beugelsdijk, S. 2010. The impact of institutional hazards on foreign multinational activity: A contingency perspective. Journal of International Business Studies, 41(6): 980-995.

Smith, P. B. 2006. When elephants fight, the grass gets trampled: The Globe and Hofstede projects. Journal of International Business Studies, 37(6): 915-921.

Smith, P. B., Dugan, S., \& Trompenaars, F. 1996. National culture and the values of organizational employees. A dimensional analysis across 43 nations. Journal of Cross-Cultural Psychology, 27(2): 231-264.

Stahl, G., \& Tung, R. 2015. Towards a more balanced treatment of culture in international Business studies: The need for 
positive cross-cultural scholarship. Journal of International Business Studies, 46(4): 391.

Stahl, G., \& Voigt, A. 2008. Do cultural differences matter in mergers and acquisitions? A tentative model and examination. Organization Science, 19(1): 160-176.

Steenkamp, J. B. 2001. The role of national culture in international marketing research. International Marketing Review, 18(1): 30-44.

Tihanyi, L., Griffith, D. A., \& Russell, C. J. 2005. The effect of cultural distance on entry mode choice, international diversification, and MNE performance: A meta-analysis. Journal of International Business Studies, 36(3): 270-283.

Tung, R. L., \& Verbeke, A. 2010. Beyond Hofstede and GLOBE: Improving the quality of cross-cultural research. Journal of International Business Studies, 41(8): 1259-1274.

Vahlne, J. E., \& Wiedersheim-Paul, F. 1973. Economic distance: Model and empirical investigation. In E. Hörnell, J. E. Vahlne, \& F. Wiedersheim-Paul (Eds.), Export and foreign establishments. Uppsala: University of Uppsala.

Valentino, A., Schmitt, J., Koch, B., \& Nell, P. C. 2018. Leaving home: An institutional perspective on intermediary HQ relocations. Journal of World Business. https://doi.org/10.1016/j. jwb.2018.08.004.

Van Hoorn, A. A. J., \& Maseland, R. 2016. How institutions matter for international business: Institutional distance effects vs institutional profile effects. Journal of International Business Studies, 47(3): 374-381.
Verbeke, A., Yuan W., \& Kano, L. (in press). A values-based analysis of bifurcation bias and its impact on family firm internationalization, Asia Pacific Journal of Management. https://doi.org/10.1007/s10490-018-9598-4.

Wu, Z., \& Salomon, R. 2016. Does imitation reduce the liability of foreignness? Linking distance, isomorphism and performance. Strategic Management Journal, 37(12): 2441-2462.

Xie, Z., \& Li, J. 2017. Exporting and innovating among emerging market firms: The moderating role of institutional development. Journal of International Business Studies, 49(2): 222-245.

Xu, D., \& Shenkar, O. 2002. Institutional distance and the multinational enterprise. Academy of Management Review, 27(4): 608-618.

Yu, S., Beugelsdijk, S., \& de Haan, J. 2015. Trade, trust and the rule of law. European Journal of Political Economy, 37: 102-115.

Zaheer, A., \& Hernandez, E. 2011. The geographic scope of the MNC and its alliance portfolio: Resolving the paradox of distance. Global Strategy Journal, 1(1-2): 109-126.

Zaheer, S., Schomaker, M., \& Nachum, L. 2012. Distance without direction: restoring credibility to a much-loved construct. Journal of International Business Studies, 43(1): 18-27.

Zhao, H., Luo, Y., \& Suh, T. 2004. Transaction cost determinants and ownership-based entry mode choice: A meta-analytical review. Journal of International Business Studies, 35(6): 524-544.

See Table 5 .

\section{APPENDIX A}

Table 5 Overview of cross-cultural frameworks

\begin{tabular}{|c|c|c|c|c|}
\hline & Hofstede framework & Schwartz value survey & Globe & WVS-EVS \\
\hline Key references & $\begin{array}{l}\text { Hofstede (1980, 2001), Hofstede } \\
\text { et al. (2010) }\end{array}$ & $\begin{array}{l}\text { Schwartz } \\
(1994,1999,2006)\end{array}$ & House et al. (2004) & $\begin{array}{l}\text { Inglehart (1990, 1997), } \\
\text { Inglehart \& Baker } \\
(2000)\end{array}$ \\
\hline Mostly used in & $\begin{array}{l}\text { Cross-cultural psychology, } \\
\text { Management }\end{array}$ & $\begin{array}{l}\text { Cross cultural } \\
\text { psychology, } \\
\text { Management }\end{array}$ & Management & $\begin{array}{l}\text { Sociology, Political } \\
\text { science, Economics }\end{array}$ \\
\hline Respondents & 117,000 & 75,148 & $7794^{a}$ & 495,000 \\
\hline Sample & $\begin{array}{l}\text { IBM employees ( } 4 \text { dimensions) and } \\
\text { stratified samples of adults ( } 2 \\
\text { dimensions) }\end{array}$ & Teachers and students & Middle managers & $\begin{array}{l}\text { Stratified samples of } \\
\text { adults }\end{array}$ \\
\hline $\begin{array}{l}\text { Country } \\
\text { coverage }\end{array}$ & $\begin{array}{l}70 \text { for first } 4 \text { dimensions } \\
62 \text { for all } 6 \text { dimensions }\end{array}$ & 71 & 58 & 110 \\
\hline Year coverage & $\begin{array}{l}1968-1972 \text { for IBM data } \\
2000 \text { s for } 5 \text { th and } 6 \text { th dimensions }\end{array}$ & 1988-2005 & 1995-1997 & $\begin{array}{l}1981-2014 \text { with } \\
\text { irregular intervals }\end{array}$ \\
\hline $\begin{array}{l}\text { Availability of } \\
\text { individual "raw" } \\
\text { data }\end{array}$ & No & $\begin{array}{l}\text { Yes, publicly available } \\
\text { from Israeli Science } \\
\text { Foundation }\end{array}$ & $\begin{array}{l}\text { No, not made } \\
\text { available }\end{array}$ & $\begin{array}{l}\text { Yes, publicly available } \\
\text { from the WVS and EVS } \\
\text { website }\end{array}$ \\
\hline Number of & $4+2$ & $7^{\mathrm{b}}$ & $9(\times 2)$ & Not predefined; \\
\hline dimensions & $\begin{array}{l}\text { Two dimensions were added } \\
40 \text { years later }\end{array}$ & & $\begin{array}{l}\text { Globe distinguishes } \\
\text { between values and } \\
\text { practices }\end{array}$ & $\begin{array}{l}\text { Inglehart (1990) defined } \\
\text { two }\end{array}$ \\
\hline $\begin{array}{l}\text { Nature of } \\
\text { questions }\end{array}$ & $1-5$ scale & $1-7$ scale & $1-7$ scale & A mix of $1-10 ; 0-1 ; 1-4$ \\
\hline
\end{tabular}


Table 5 (Continued)

\begin{tabular}{|c|c|c|c|c|}
\hline & Hofstede framework & Schwartz value survey & Globe & WVS-EVS \\
\hline \multirow[t]{7}{*}{$\begin{array}{l}\text { Cultural } \\
\text { dimensions }\end{array}$} & 1. Collectivism-Individualism & 1. Harmony & $\begin{array}{l}\text { 1. Uncertainty } \\
\text { Avoidance }\end{array}$ & \multirow{7}{*}{$\begin{array}{l}\text { Inglehart defined two: } \\
\text { 1. Traditional-secular/ } \\
\text { rational } \\
\text { 2. Survival-self- } \\
\text { expression }\end{array}$} \\
\hline & 2. Power Distance & 2. Embeddedness & 2. Future Orientation & \\
\hline & 3. Masculinity & 3. Hierarchy & 3. Power Distance & \\
\hline & 4. Uncertainty Avoidance & 4. Mastery & $\begin{array}{l}\text { 4. Institutional } \\
\text { Collectivism }\end{array}$ & \\
\hline & 5. Long-term orientation & 5. Affective Autonomy & 5. Humane orientation & \\
\hline & 6. Indulgence versus Restraint & 6. Intellectual Autonomy & $\begin{array}{l}\text { 6. Performance } \\
\text { Orientation }\end{array}$ & \\
\hline & $\begin{array}{l}\text { Dimensions } 5 \text { and } 6 \text { were added } \\
\text { later. }\end{array}$ & 7. Egalitarianism & $\begin{array}{l}\text { 7. In-group } \\
\text { Collectivism } \\
\text { 8. Gender } \\
\text { Egalitarianism } \\
\text { 9. Assertiveness }\end{array}$ & \\
\hline
\end{tabular}

a House et al. (2004) mention a total of 15,000, but it should be noted that approximately half of this sample has been used to collect data on leadership, and 7794 respondents for the survey on national cultural values. Of these 7794 respondents, Sweden stands out with a total of 895 respondents (based on personal communication from Paul Hanges).

${ }^{b}$ Note that Schwartz $(1994,1999,2006)$ distinguishes between personal values and national cultural (societal) orientations. The number of dimensions and the meaning of those dimensions are not the same at the individual and societal level. At the societal level, Schwartz conceptualizes cultural values as "the normative value emphases that underlie societal functioning" (Schwartz, 2011: 314). Here, we refer to the seven national cultural orientations (Schwartz, 2006). For a recent analysis discussing Schwartz' two frameworks in the context of internationalization strategy, see Verbeke, Yuan \& Kano (in press). Hofstede has stated explicitly that his framework is a national cultural framework and thus cannot be used at the individual level (Hofstede, 2001).

See Table 6.

\section{APPENDIX B}

Table 6 Correlation table of Hofstede's dimensions, Schwartz's dimensions and Globe's value dimensions

\begin{tabular}{|c|c|c|c|c|c|c|c|c|c|c|c|c|}
\hline & Cultural dimensions & & 1 & 2 & 3 & 4 & 5 & 6 & 7 & 8 & 9 & 10 \\
\hline 1 & Collectivism-Individualism & $\mathrm{H}$ & 1 & & & & & & & & & \\
\hline 2 & Power Distance & $\mathrm{H}$ & -.62 & 1 & & & & & & & & \\
\hline 3 & Masculinity & $\mathrm{H}$ & .07 & .13 & 1 & & & & & & & \\
\hline 4 & Uncertainty Avoidance & $\mathrm{H}$ & -.22 & .23 & -.07 & 1 & & & & & & \\
\hline 5 & Long-term Orientation & $\mathrm{H}$ & .07 & .05 & .01 & -.02 & 1 & & & & & \\
\hline 6 & Indulgence versus Restraint & $\mathrm{H}$ & .16 & -.31 & .09 & -.07 & -.43 & 1 & & & & \\
\hline 7 & Harmony & $\mathrm{S}$ & .21 & -.12 & -.06 & .37 & .23 & .04 & 1 & & & \\
\hline 8 & Embeddedness & $S$ & -.55 & .62 & -.06 & -.03 & -.34 & -.21 & -.43 & 1 & & \\
\hline 9 & Hierarchy & $S$ & -.48 & .43 & .16 & -.23 & -.01 & -.23 & -.62 & .50 & 1 & \\
\hline 10 & Mastery & $S$ & -.22 & .11 & .14 & -.06 & .00 & -.12 & -.48 & -.13 & .46 & 1 \\
\hline 11 & Affective Autonomy & $S$ & .67 & -.61 & .00 & -.13 & .35 & .13 & .22 & -.87 & -.40 & .21 \\
\hline 12 & Intellectual Autonomy & $S$ & .43 & -.42 & .07 & .14 & .30 & .13 & .57 & -.85 & -.57 & -.11 \\
\hline 13 & Egalitarianism & $\mathrm{S}$ & .43 & -.47 & -.10 & .05 & -.25 & .49 & .43 & -.43 & -.63 & -.45 \\
\hline 14 & Uncertainty Avoidance & G & -.72 & .72 & .07 & .32 & -.27 & -.25 & -.24 & .76 & .47 & .13 \\
\hline 15 & Future Orientation & G & -.49 & .58 & .13 & .29 & -.42 & -.06 & -.32 & .61 & .32 & .13 \\
\hline 16 & Power Distance & G & .15 & -.01 & .15 & -.46 & .05 & -.29 & -.31 & .38 & .42 & .08 \\
\hline 17 & Institutional Collectivism & G & -.52 & .36 & .01 & .37 & -.34 & .16 & .14 & .16 & .02 & .08 \\
\hline 18 & Humane Orientation & G & .20 & -.10 & .01 & -.06 & .01 & .08 & -.09 & -.02 & -.01 & -.18 \\
\hline 19 & Performance Orientation & G & -.15 & .15 & .04 & .16 & -.59 & .38 & .06 & .12 & -.24 & -.09 \\
\hline 20 & In-group Collectivism & G & -.26 & .20 & -.16 & .24 & -.61 & .41 & -.06 & .23 & -.04 & -.02 \\
\hline 21 & Gender Egalitarianism & G & .42 & -.46 & -.02 & .06 & -.05 & .55 & .30 & -.69 & -.52 & .01 \\
\hline 22 & Assertiveness & G & -.17 & .29 & .15 & -.38 & .09 & -.29 & -.39 & .27 & .51 & .23 \\
\hline
\end{tabular}


1134

Table 6 continued

$$
\text { Cultural dimensions }
$$

12

13

14

15

16

17

18

$19 \quad 20$

21

1 Collectivism-Individualism $\mathrm{H}$

2 Power Distance $\mathrm{H}$

3 Masculinity $\mathrm{H}$

4 Uncertainty Avoidance $\mathrm{H}$

5 Long-term Orientation $\mathrm{H}$

6 Indulgence versus Restraint $\mathrm{H}$

7 Harmony S

8 Embeddedness S

9 Hierarchy S

10 Mastery S

11 Affective Autonomy S

12 Intellectual Autonomy S

13 Egalitarianism S

14 Uncertainty Avoidance
15 Future Orientation

16 Power Distance

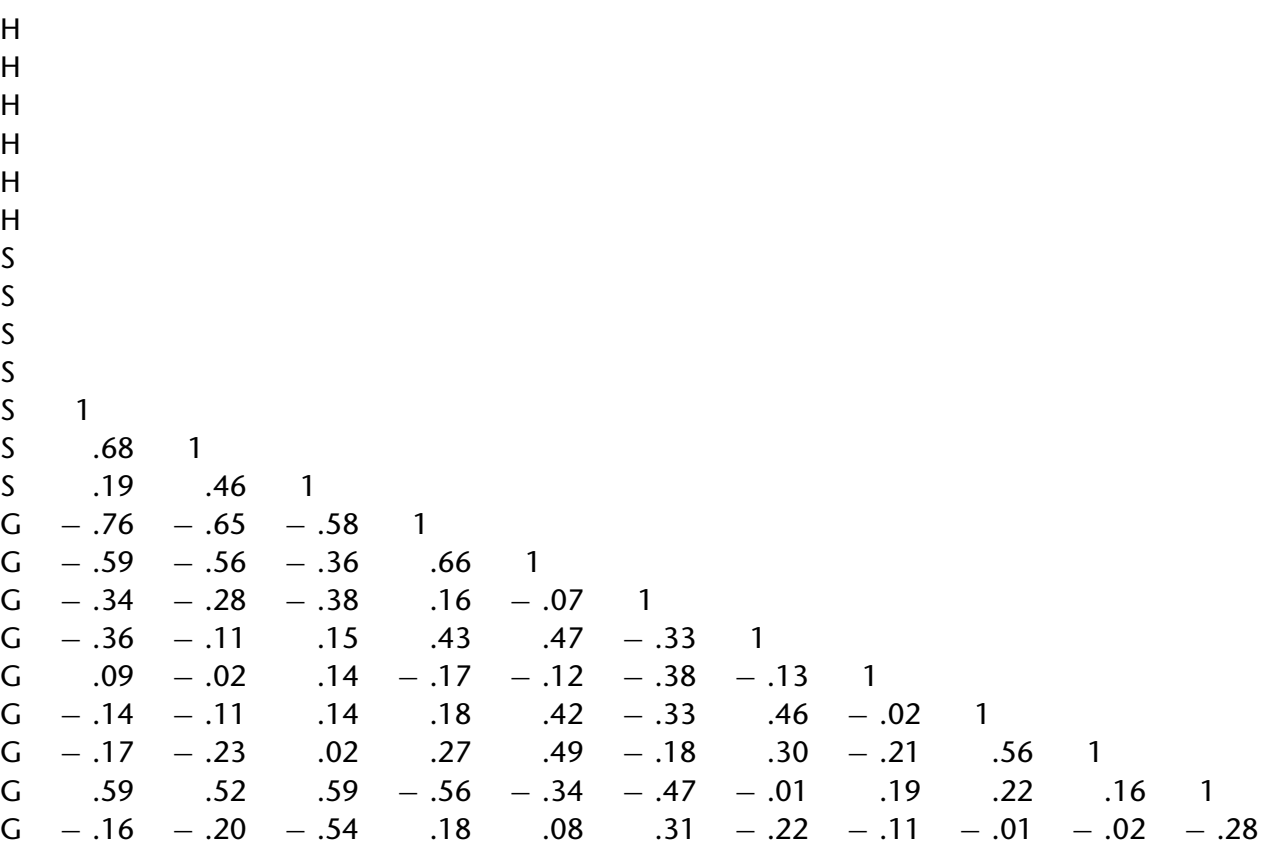

17 Institutional Collectivism

18 Humane Orientation

19 Performance Orientation

20 In-group Collectivism

21 Gender Egalitarianism

22 Assertiveness

$\mathrm{G}-.16$

All correlations larger than |.02| are significant at .05.

$H$ Hofstede; S Schwartz; $G$ Globe. 


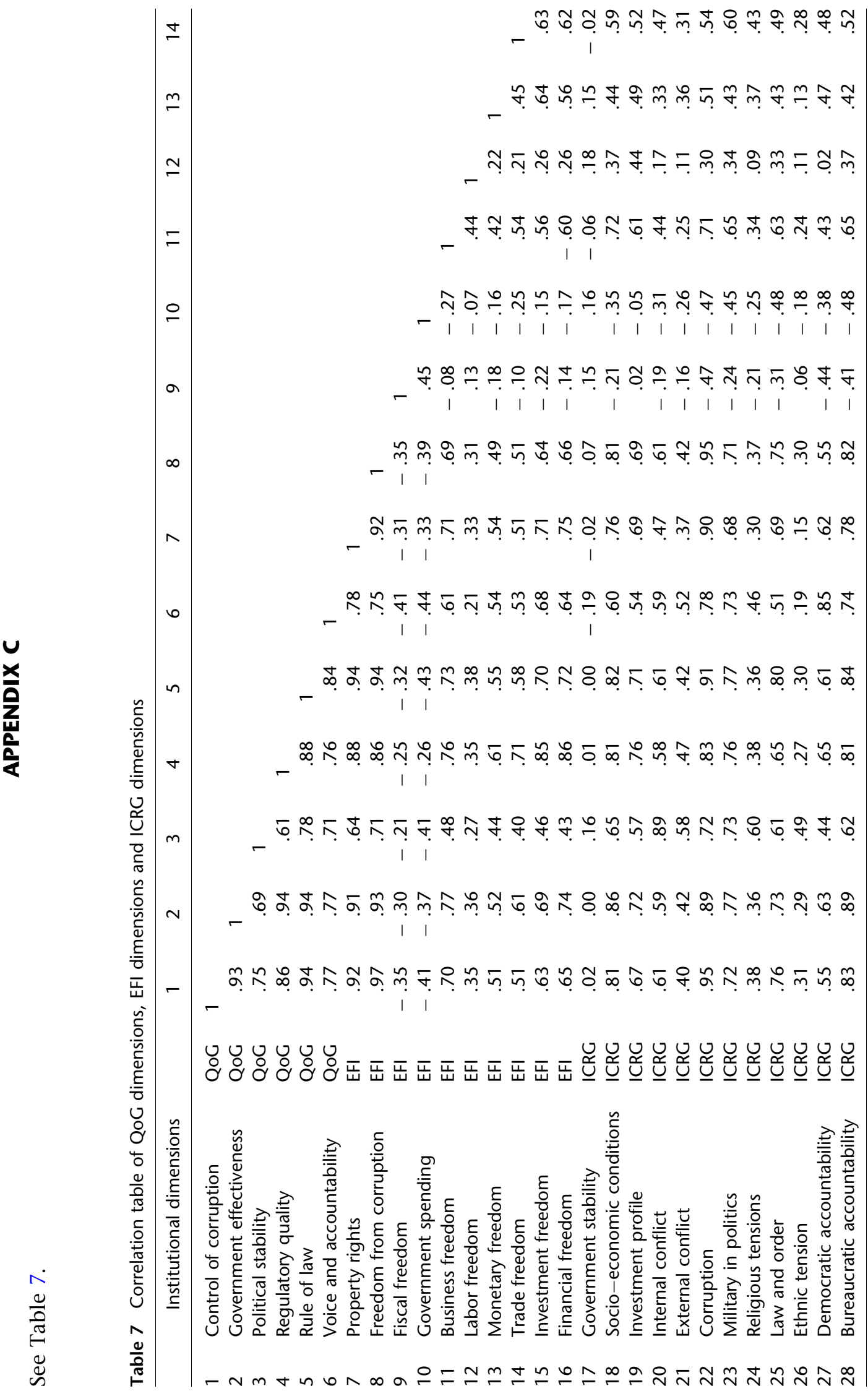




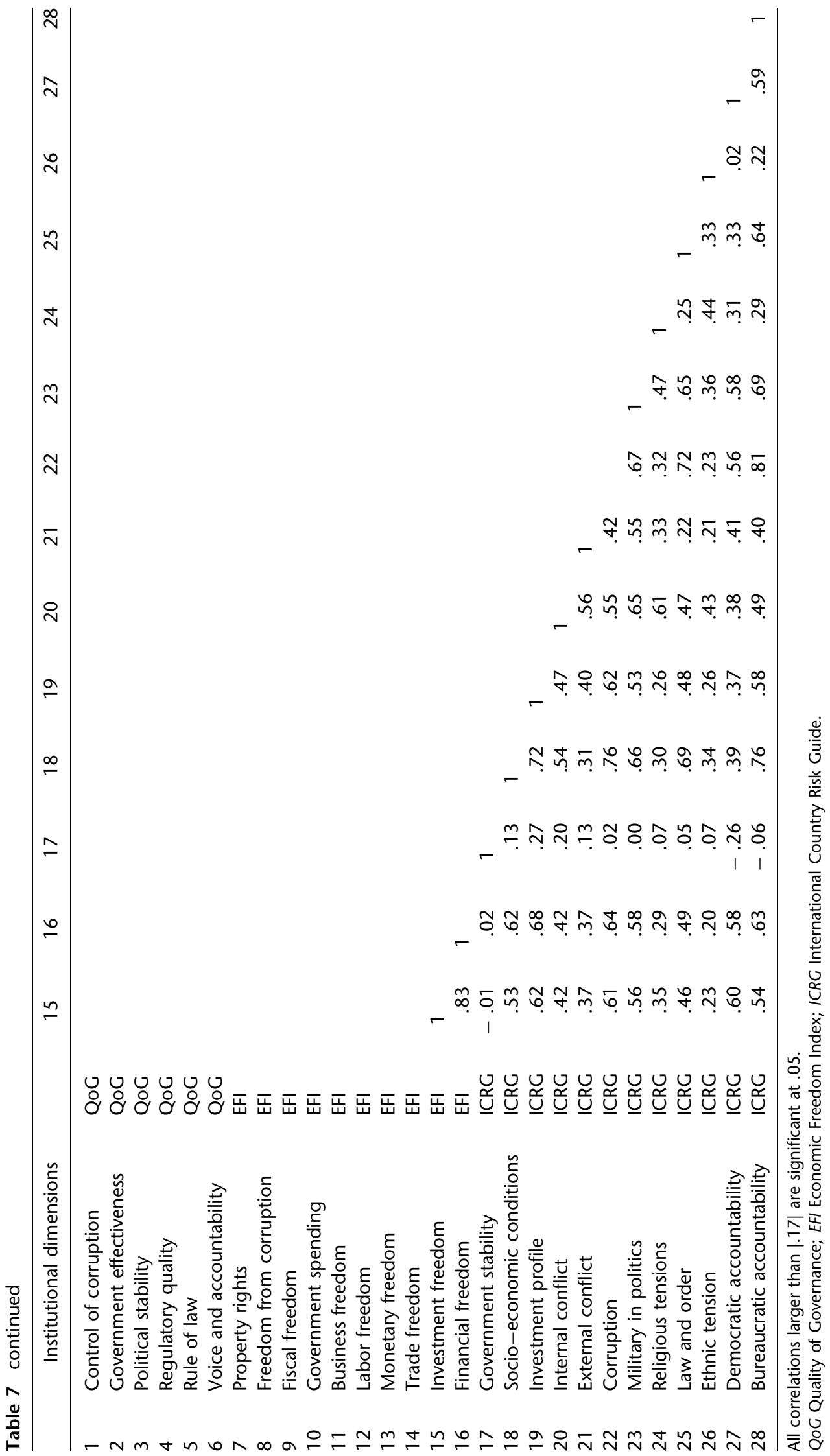


See Table 8 .

APPENDIX D

Table 8 Factor analysis of Hofstede's six dimensional model

\begin{tabular}{|c|c|c|c|}
\hline \multirow[b]{2}{*}{ Hofstede dimensions } & \multicolumn{3}{|c|}{$\begin{array}{l}\text { (Rotated) Factor loadings } \\
\text { Three-factor solution }\end{array}$} \\
\hline & $\begin{array}{c}\text { Factor } 1 \\
\text { (explains 30\%) }\end{array}$ & $\begin{array}{c}\text { Factor } 2 \\
\text { (explains } 25 \% \text { ) }\end{array}$ & $\begin{array}{c}\text { Factor } 3 \\
\text { (explains 17\%) }\end{array}$ \\
\hline Power distance & .85 & .15 & .20 \\
\hline Individualism & -.87 & .03 & .08 \\
\hline Masculinity & .04 & -.02 & .98 \\
\hline Uncertainty Avoidance & .47 & -.07 & -.07 \\
\hline Long-term Orientation & -.12 & .88 & .07 \\
\hline Indulgence versus Restraint & -.26 & -.84 & .11 \\
\hline
\end{tabular}

$n=62$ countries. The analysis results in three factors with eigenvalues larger than 1 , explaining $72 \%$ of the variation across all six dimensions.

Open Access This article is distributed under theterms of the Creative Commons Attribution 4.0International License (http://creativecommons. org/licenses/by/4.0/), which permits unrestricteduse, distribution, and reproduction in any medium,provided you give appropriate credit to the originalauthor(s) and the source, provide a link to theCreative Commons license, and indicate if changeswere made.

\section{ABOUT THE AUTHORS}

Sjoerd Beugelsdijk is a Professor of International Business and Management at the University of Groningen, the Netherlands. He earned his PhD at Tilburg University and explores how cultural diversity affects international business. He is currently serving as Reviewing Editor for JIBS.
Björn Ambos is a Professor of Strategic Management and Director at the Institute of Management of the University of St. Gallen. He currently serves as a Senior Editor of the Journal of World Business. His current research focuses on psychic distance as well as headquarters-subsidiary relationships within the MNC. Björn's work has been published in journals such as Strategic Management Journal, Organization Science, Journal of World Business, Journal of International Management, Long Range Planning, and Research Policy.

Phillip C Nell is a Professor at WU Wien (Vienna University of Economics and Business) where he received his PhD. He is also affiliated with Copenhagen Business School where he held faculty positions before rejoining WU. His work has appeared in the Strategic Management Journal, Journal of Management, Journal of Management Studies, and several other outlets. 